\title{
Endoscopic management of acute necrotizing pancreatitis: European Society of Gastrointestinal Endoscopy (ESGE) evidence-based multidisciplinary guidelines
}

Authors

Marianna Arvanitakis ${ }^{1}$, Jean-Marc Dumonceau ${ }^{2}$, Jörg Albert ${ }^{3}$, Abdenor Badaoui ${ }^{4}$, Maria Antonietta Bali ${ }^{1}$, Marc Barthet $^{5}$, Marc Besselink ${ }^{6}$, Jacques Deviere ${ }^{1}$, Alexandre Oliveira Ferreira ${ }^{7}$, Tibor Gyökeres ${ }^{8}$, Istvan Hritz ${ }^{9}$, Tomas Hucl $^{10}$, Marianna Milashka ${ }^{11}$, Ioannis S. Papanikolaou ${ }^{12}$, Jan-Werner Poley ${ }^{13}$, Stefan Seewald ${ }^{14}$, Geoffroy Vanbiervliet ${ }^{15}$, Krijn van Lienden ${ }^{16}$, Hjalmar van Santvoort ${ }^{17}$, Rogier Voermans ${ }^{18}$, Myriam Delhaye ${ }^{1}$, Jeanin van Hooft $^{18}$

\section{Institutions}

1 Department of Gastroenterology, Hepatology and Digestive Oncology, Erasme University Hospital Université Libre de Bruxelles, Brussels, Belgium

2 Gedyt Endoscopy Center, Buenos Aires, Argentina

3 Robert-Bosch-Krankenhaus, Abteilung für Gastroenterologie, Hepatologie und Endokrinologie, Stuttgart, Germany

4 Department of Gastroenterology and Hepatology, Université catholique de Louvain, CHU UCL Namur, Yvoir, Belgium

5 Service d'Hépato-gastroentérologie, Hôpital Nord, Marseille, France

6 Department of Surgery, Amsterdam Gastroenterology and Metabolism, Academic Medical Center Amsterdam, Amsterdam, The Netherlands

7 Gastroenterology Unit, Department of Surgery, Hospital Beatriz Ângelo, Loures, Portugal

8 Dept. of Gastroenterology, Medical Centre Hungarian Defense Forces, Budapest, Hungary

9 Semmelweis University, 1st Department of Surgery, Endoscopy Unit, Budapest, Hungary

10 Department of Gastroenterology and Hepatology, Institute of Clinical and Experimental Medicine, Prague, Czech Republic

11 Service de Gastroentérologie et Hépatologie, Hôpital Desgenettes, Lyon, France

12 Hepatogastroenterology Unit, Second Department of Internal Medicine, Propaedeutic, Research Institute and Diabetes Center, Medical School, National and Kapodistrian University, Attikon University General Hospital, Athens, Greece

13 Department of Gastroenterology and Hepatology, Erasmus MC, University Medical Center, Rotterdam, The Netherlands
14 Gastroenterologie, Klinik Hirslanden, Zurich, Switzerland

15 Centre Hospitalier Universitaire de Nice, Pole D.A.R.E, Endoscopie Digestive, Nice, France

16 Department of Radiology, Academic Medical Center, University of Amsterdam, Amsterdam, The Netherlands

17 Department of Surgery, St. Antonius Hospital Nieuwegein, The Netherlands and Department of Surgical Oncology, University Medical Center Utrecht Cancer Center, The Netherlands

18 Department of Gastroenterology and Hepatology, Academic Medical Center, University of Amsterdam, Amsterdam, The Netherlands

Bibliography

DOI https://doi.org/10.1055/a-0588-5365

Published online: 9.4.2018 | Endoscopy 2018; 50: 524-546

(c) Georg Thieme Verlag KG Stuttgart · New York

ISSN 0013-726X

Corresponding author

Marianna Arvanitakis, MD PhD, Department of Gastroenterology, Hepatopancreatology and Digestive Oncology, Erasme University Hospital, Université Libre de Bruxelles, Route de Lennik 808, 1070 Brussels, Belgium Marianna.Arvanitaki@erasme.ulb.ac.be

\#ables e1-e16

Online content viewable at:

https://doi.org/10.1055/a-0588-5365 


\section{MAIN RECOMMENDATION}

1 ESGE suggests using contrast-enhanced computed tomography $(\mathrm{CT})$ as the first-line imaging modality on admission when indicated and up to the 4th week from onset in the absence of contraindications. Magnetic resonance imaging (MRI) may be used instead of CT in patients with contraindications to contrast-enhanced CT, and after the 4th week from onset when invasive intervention is considered because the contents (liquid vs. solid) of pancreatic collections are better characterized by MRI and evaluation of pancreatic duct integrity is possible.

Weak recommendation, low quality evidence.

2 ESGE recommends against routine percutaneous fine needle aspiration (FNA) of (peri)pancreatic collections. Strong recommendation, moderate quality evidence.

FNA should be performed only if there is suspicion of infection and clinical/imaging signs are unclear.

Weak recommendation, low quality evidence.

3 ESGE recommends initial goal-directed intravenous fluid therapy with Ringer's lactate (e.g. $5-10 \mathrm{~mL} / \mathrm{kg} / \mathrm{h}$ ) at onset. Fluid requirements should be patient-tailored and reassessed at frequent intervals.

Strong recommendation, moderate quality evidence.

4 ESGE recommends against antibiotic or probiotic prophylaxis of infectious complications in acute necrotizing pancreatitis.

Strong recommendation, high quality evidence.
5 ESGE recommends invasive intervention for patients with acute necrotizing pancreatitis and clinically suspected or proven infected necrosis.

Strong recommendation, low quality evidence.

ESGE suggests that the first intervention for infected necrosis should be delayed for 4 weeks if tolerated by the patient. Weak recommendation, low quality evidence.

6 ESGE recommends performing endoscopic or percutaneous drainage of (suspected) infected walled-off necrosis as the first interventional method, taking into account the location of the walled-off necrosis and local expertise.

Strong recommendation, moderate quality evidence.

7 ESGE suggests that, in the absence of improvement following endoscopic transmural drainage of walled-off necrosis, endoscopic necrosectomy or minimally invasive surgery (if percutaneous drainage has already been performed) is to be preferred over open surgery as the next therapeutic step, taking into account the location of the walled-off necrosis and local expertise.

Weak recommendation, low quality evidence.

8 ESGE recommends long-term indwelling of transluminal plastic stents in patients with disconnected pancreatic duct syndrome.

Strong recommendation, low quality evidence.

Lumen-apposing metal stents should be retrieved within 4 weeks to avoid stent-related adverse effects.

Strong recommendation, low quality evidence.
This Guideline is an official statement of the European Society of Gastrointestinal Endoscopy (ESGE) on the management of acute necrotizing pancreatitis. The Grading of Recommendations Assessment, Development and Evaluation (GRADE) system was adopted to define the strength of recommendations and the quality of evidence.

\section{Introduction}

Acute pancreatitis is the most common gastrointestinal disease requiring acute hospital admission [1]. In most cases (80\%), the outcome is rapidly favorable [2]. However, acute necrotizing pancreatitis (ANP) may develop in up to $20 \%$ of cases and is associated with significant rates of early organ failure (38\%), need for intervention (38\%), and death (15\%) [3]. Among interventions, necrosectomy through the endoscopic route is increasingly performed.

This evidence-based guideline was commissioned by the European Society of Gastrointestinal Endoscopy (ESGE). It aims to address all major issues concerning the global management of ANP, the roles of radiology, endoscopy, and surgery in step-up strategies, and the technical modalities of endoscopic necrosectomy.

\section{Methods}

The ESGE commissioned this guideline and appointed a guideline leader (M.A.) who invited the listed authors to participate in the project development. The key questions were prepared by the coordinating team (M.A., M.D.) and then approved by the other members. The coordinating team formed task force subgroups, each with their own leader, and divided the key topics among the subgroups. Topics included: diagnosis and initial management, indications and timing for intervention, treatment modalities (radiological, endoscopic, and surgical, as well as combined), complications, and outcome. The guideline development process included meetings and online discussions that took place from October 2015 to October 2016.

A literature search of PubMed/MEDLINE, the Cochrane Library, and Embase was performed by the authors for papers published on this topic up to December 2016. The search focused on fully published randomized controlled trials (RCTs) and meta-analyses. Retrospective analyses and case series were also included if they addressed topics not covered in the prospective studies. For important outcomes, articles were individually assessed by means of the Grading of Recommendations Assessment, Development, and Evaluation (GRADE) sys- 


\begin{tabular}{|c|c|}
\hline \multicolumn{2}{|c|}{ ABBREVIATIONS } \\
\hline ANP & acute necrotizing pancreatitis \\
\hline APA & American Pancreatic Association \\
\hline AUC & area under the curve \\
\hline BISAP & bedside index of severity in acute pancreatitis \\
\hline BUN & blood urea nitrogen \\
\hline CE-CT & $\begin{array}{l}\text { contrast-enhanced computed tomography } \\
\text { scan }\end{array}$ \\
\hline $\mathrm{Cl}$ & confidence interval \\
\hline CRP & C-reactive protein \\
\hline CTSI & CT severity index \\
\hline DBC & determinant-based classification \\
\hline DEN & $\begin{array}{l}\text { direct transluminal endoscopic necrosect- } \\
\text { omy }\end{array}$ \\
\hline DPDS & disconnected pancreatic duct syndrome \\
\hline ERCP & $\begin{array}{l}\text { endoscopic retrograde cholangiopancreato- } \\
\text { graphy }\end{array}$ \\
\hline ESGE & $\begin{array}{l}\text { European Society of Gastrointestinal Endos- } \\
\text { copy }\end{array}$ \\
\hline EUS & endoscopic ultrasound \\
\hline EXPN & extrapancreatic (peripancreatic) necrosis \\
\hline FC-SEMS & fully covered self-expandable metal stent \\
\hline FNA & fine needle aspiration \\
\hline GRADE & $\begin{array}{l}\text { Grading of Recommendations Assessment, } \\
\text { Development, and Evaluation }\end{array}$ \\
\hline IAP & International Association of Pancreatology \\
\hline ICU & intensive care unit \\
\hline IPN & $\begin{array}{l}\text { infected pancreatic and/or peripancreatic } \\
\text { necrosis }\end{array}$ \\
\hline LAMS & lumen-apposing metal stent \\
\hline MPD & main pancreatic duct \\
\hline MRCP & $\begin{array}{l}\text { magnetic resonance cholangio- } \\
\text { pancreatography }\end{array}$ \\
\hline MRI & magnetic resonance imaging \\
\hline MTGT & multiple transluminal gateway technique \\
\hline OR & odds ratio \\
\hline PCD & percutaneous catheter drainage \\
\hline PFC & pancreatic fluid collection \\
\hline RAC & revised Atlanta classification \\
\hline RCT & randomized controlled trial \\
\hline SIRS & systemic inflammatory response syndrome \\
\hline VARD & video-assisted retroperitoneal debridement \\
\hline WON & walled-off necrosis \\
\hline
\end{tabular}

tem for grading evidence levels and recommendation strengths [4].

Each subgroup developed draft proposals that were discussed electronically and then during a meeting held in May 2016 (Brussels, Belgium). After agreement on a final version following a meeting in October 2016 (Vienna, Austria), the manuscript was reviewed by two experts selected by the ESGE Governing Board and then sent to all ESGE-affiliated societies and individual members. After agreement on a final version, the manuscript was submitted to the journal Endoscopy for publication. All authors agreed on the final revised manuscript.
This Guideline will be considered for review in 2021 or sooner if new and relevant evidence becomes available. Any updates to the Guideline in the interim will be noted on the ESGE website: http://www.esge.com/esge-guidelines.html.

\section{Diagnosis}

\subsection{Classification systems for acute pancreatitis severity: revised Atlanta classification and determinant-based classification}

\section{RECOMMENDATION}

ESGE suggests using the 3-tiered revised Atlanta classification rather than the 4-tiered determinant-based classification.

Weak recommendation, low quality evidence.

\section{RECOMMENDATION}

ESGE suggests considering, besides the level of severity, the presence or absence of infected necrosis, as well as multiple vs. single persistent organ failure as further predictors of outcome.

Weak recommendation, low quality evidence.

Four levels of severity are distinguished in the determinantbased classification (DBC): (i) mild (absence of both [peri]pancreatic necrosis and organ failure), (ii) moderate (presence of sterile [peri]pancreatic necrosis and/or transient organ failure), (iii) severe (presence of either infected [peri]pancreatic necrosis or persistent organ failure), and (iv) critical (presence of infected [peri]pancreatic necrosis and persistent organ failure) [5]. On the other hand, the revised Atlanta classification (RAC) defines three degrees of severity: (i) mild (absence of organ failure and absence of local or systemic complications), (ii) moderate (presence of transient organ failure and/or local or systemic complications), and (iii) severe (presence of persistent organ failure, single or multiple) [6].

Unlike the RAC, the DBC requires data on [peri]pancreatic necrosis status, sterile or infected, and is therefore less applicable during the early phase (1st week), being more suitable for post-hoc category allocation [7]. Both the RAC and the DBC were found to be similar in terms of predicting important clinical outcomes in acute pancreatitis (mortality, need for intensive care unit [ICU] management, need for intervention, and duration of hospital stay) [8-11]. The addition of a critical category in the DBC identifies patients with the most severe disease [7-13]. However, the proportion of patients included in this critical category was low $(0.6 \%-12 \%)$; therefore, the clinical significance of this group is probably limited.

In most studies, patients with infected pancreatic and/or peripancreatic necrosis (IPN) seemed to have poorer outcomes, independently of whether they were initially classified as moderate or severe [14-16]. Both classifications failed to account for the impact of persistent multiple-organ failure vs. persist- 
ent single-organ failure on mortality (56.3\% vs. $7.4 \%$; $P=0.001$ ) [10] (Table e1, available online in Supplementary material).

\subsection{Definition of local complications of acute pancreatitis}

The local complications of acute pancreatitis are best defined in the RAC [6] and include acute (peri)pancreatic fluid collections (PFCs; within the first 4 weeks, with no well-defined wall, usually resolving spontaneously); acute necrotic collections (within the first 4 weeks, containing variable amounts of fluid and necrotic tissue, arising from ANP); pancreatic pseudocysts ( $\geq 4$ weeks after onset of interstitial acute pancreatitis, fluid collection in the [peri]pancreatic tissues, surrounded by a well-defined wall, containing no solid material); and walled-off necrosis (WON; after $\geq 4$ weeks, encapsulated collection containing partially liquefied [peri]pancreatic necrotic tissue). Other local complications include abdominal compartment syndrome, gastric outlet dysfunction, biliary obstruction, splenic and portal vein thrombosis, colonic necrosis, major bleeding, ascites, and pleural effusions [1, 17].

\subsection{Definition of necrosis, extrapancreatic necrosis, and infected necrosis}

In ANP, necrosis may involve the pancreatic parenchyma alone ( $<5 \%$ of cases), the pancreatic parenchyma and peripancreatic tissues $(75 \%-80 \%$ of cases), or peripancreatic tissues alone (approximately $20 \%$ of cases) [18].

Pancreatic necrosis is the presence of non-viable pancreatic parenchyma. It is commonly assessed as a focal or diffuse area with no enhancement on contrast-enhanced computed tomography scanning (CE-CT) $[6,19]$. By magnetic resonance imaging (MRI), pancreatic necrosis appears as well-marginated areas of lower signal intensity compared with the signal intensity of the normal pancreas and spleen in non-enhanced MRI and in the arterial, early venous, and late venous phases of enhancement after intravenous gadolinium injection [20].

Extrapancreatic (peripancreatic) necrosis (EXPN) is defined as the presence of heterogeneous, peripancreatic, ill-defined areas, commonly located in the retroperitoneum and lesser sac, while the pancreas enhances normally on CE-CT [21].

In a prospective study (639 patients), compared with patients with pancreatic necrosis, patients with EXPN alone had lower risks of organ failure (adjusted odds ratio [OR] 0.53), multiple-organ failure (adjusted OR 0.48), IPN (adjusted OR 0.30 ), need for intervention (adjusted OR 0.25), and mortality (adjusted OR 0.59). However, in the case of IPN, morbidity and mortality rates were similar among patients with EXPN and those with parenchymal pancreatic necrosis (with or without EXPN) [22].

IPN can be suspected based on clinical evidence of sepsis (e. g. fever $>38^{\circ} \mathrm{C}$, features of persistent systemic inflammatory response syndrome (SIRS), and deterioration or no improvement in clinical condition) or the presence of extraluminal gas in the pancreatic and/or peripancreatic tissues on CT [23]. IPN is diagnosed when sampling of (peri)pancreatic tissue by percutaneous, endoscopic, or surgical drainage is positive for bacteria and/or fungi on Gram stain or culture.

\subsection{Scores and/or markers for the prediction of severe acute pancreatitis on admission and at 48 hours}

\section{RECOMMENDATION}

ESGE suggests using the Bedside Index of Severity in Acute Pancreatitis (BISAP) score within the first 24 hours of presentation as an early predictor of severity and mortality in acute pancreatitis.

Weak recommendation, moderate quality evidence.

\section{RECOMMENDATION}

ESGE suggests using a blood urea nitrogen (BUN) level $\geq$ $23 \mathrm{mg} / \mathrm{dL}(8.2 \mathrm{mmol} / \mathrm{L})$ as a predictor of persistent organ failure after 48 hours of admission.

Weak recommendation, moderate quality evidence.

Persistent organ failure is a good surrogate marker of severity in acute pancreatitis [6]. The overall accuracy of 11 scores/ markers in predicting persistent organ failure has been evaluated in two prospective cohorts $(n=256$ and $n=397)$ [24]. Overall, accuracy in predicting persistent organ failure was modest (area under the curve [AUC] 0.57-0.74 at admission and $0.57-0.79$ at 48 hours).

Individual laboratory values showed accuracy similar to that of more complex scoring systems: for example, the AUC for BUN $\geq 23 \mathrm{mg} / \mathrm{dL}$ was 0.73 at admission and 0.76 at 48 hours [24]. In a post-hoc retrospective analysis of three prospectively enrolled cohorts of 1612 patients with acute pancreatitis, a hematocrit $\geq 44 \%$ on admission and a rise in BUN at 24 hours showed the highest accuracy ( 0.67 and 0.71 , respectively) for predicting persistent organ failure [25].

In two studies, a retrospective analysis of a prospective database including 759 patients with acute pancreatitis [26] and a prospective cohort study including 252 patients [27], persistent SIRS at 48 hours was significantly associated with higher mortality. Contrary to these results, a recent systematic review examining the performance of 11 predictors of persistent organ failure within the first 48 hours from admission suggested that SIRS did not perform well [28].

Four further studies have identified a BISAP score $\geq 2$ within the first 24 hours of admission to be an accurate predictor of severe acute pancreatitis with an AUC $\geq 0.80$ for prediction of severe acute pancreatitis and an $A U C \geq 0.82$ for prediction of mortality [29-32] (Table e2, available online in Supplementary materials). 


\subsection{Indications, timing, and modalities of imaging in predicted severe acute pancreatitis}

\section{RECOMMENDATION}

ESGE suggests performing cross-sectional imaging on admission where there is diagnostic uncertainty; within the first week from onset (after 72 hours from onset of symptoms) where there is failure to respond to conservative treatment; from the 2 nd to the 4 th week, to evaluate the evolution of complications; and, after the 4th week, to plan further management and to monitor the treatment response.

Weak recommendation, very low quality evidence.

\section{RECOMMENDATION}

ESGE suggests using contrast-enhanced $C T$ as the firstline imaging modality on admission when indicated and up to the 4th week from onset in the absence of contraindications. MRI may be used instead in patients with contraindications to contrast-enhanced CT, and after the 4th week from onset when invasive intervention is considered because the contents (liquid vs. solid) of pancreatic collections are better characterized by MRI and evaluation of pancreatic duct integrity is possible. Weak recommendation, low quality evidence.

\section{RECOMMENDATION}

ESGE recommends use of the CT severity index as the preferred imaging severity score.

Strong recommendation, moderate quality evidence.

At admission, imaging with CE-CT is indicated where there is uncertainty about the diagnosis of acute pancreatitis [3335]. Furthermore, abdominal ultrasound plays a role in determination of the etiology of acute pancreatitis (biliary vs. other origin), and should be performed on admission.

Within the first week from onset/hospital admission, patients with predicted severe acute pancreatitis who fail to improve clinically despite conservative treatment should have imaging in order to stage the extent of pancreatic necrosis (both parenchymal and extrapancreatic) and to identify early complications [34,36]. CE-CT best detects parenchymal pancreatic necrosis 72 hours after symptom onset; before that time, it may underestimate or miss the presence of necrosis [35]. CE-CT is the first-line imaging modality used to assess the morphological features of ANP $[19,35,37]$ because it is widely available with a short scan duration, a robust reproducibility (high interobserver and intraobserver agreement), and a high accuracy for predicting severe acute pancreatitis and clinical outcome [31,37-39]. For example, the AUC of the CT se- verity index (CTSI) using a cutoff of 3 for predicting persistent organ failure is 0.84 [31], and 0.85 with a CTSI cutoff of 4 [38].

Non-enhanced MRI is similar to CE-CT for the early assessment of acute pancreatitis severity [20, 39-41]. MRI (without gadolinium) can be recommended when the injection of iodinated contrast medium is contraindicated (i.e. impaired renal function or allergy to iodinated contrast) or when radiation exposure is contraindicated (i.e. pregnant women). Contrast-enhanced ultrasound could also be used, potentially at the bedside, as it presents similar accuracy to CE-CT for the detection of severe acute pancreatitis [42-44]. However, its applicability may be more limited (e.g. obesity, meteorism).

From the 2 nd to the 4 th week after onset/hospital admission, imaging aims to detect local complications (e.g. vascular complications, main pancreatic duct [MPD] disruption), evaluate the evolution of (peri)pancreatic local complications (acute necrotic collection), or assess patients in whom a severe complication such as bleeding, bowel ischemia, or perforation is suspected [34]. MPD disruption is best diagnosed by secretinenhanced magnetic resonance cholangiopancreatography (MRCP) [45].

After the 4th week, imaging is used in patients with no clinical improvement, if invasive intervention is considered, and to monitor treatment response. MRI is preferred to assess whether WON can be drained because it is better at detecting non-liquefied material than $\mathrm{CT}$, with a better interobserver agreement $[46,47]$ ( Fig.1a). Albeit more invasive, endoscopic ultrasound (EUS) is also accurate in assessing the content of WON $[48,49]$.

\subsection{Differentiating between sterile and infected necrosis (including clinical, biological, and imaging modalities)}

\section{RECOMMENDATION}

ESGE recommends against routine percutaneous fine needle aspiration (FNA) of (peri)pancreatic collections. Strong recommendation, moderate quality evidence. FNA should be performed only if there is suspicion of infection and clinical/imaging signs are unclear. Weak recommendation, low quality evidence.

A Dutch post-hoc retrospective analysis of a prospective multicenter database (208 patients) found that clinical deterioration (persisting sepsis, new/prolonged organ failure, increased need for cardiovascular and/or respiratory and/or renal support, leukocytosis, elevated or increasing C-reactive protein [CRP], and fever) despite adequate support, in the absence of an alternative source of infection, was caused by IPN in 74 of 92 patients (80.4\%; false-positive rate $19.6 \%$ ) [50].

A systematic review suggested that the best biological predictor of IPN is procalcitonin. With a cutoff value of $3.5 \mathrm{ng} / \mathrm{mL}$, procalcitonin had a sensitivity and specificity of 0.90 and 0.89 , respectively [28]. However, procalcitonin is a non-specific marker of infective complications in critically ill patients and 

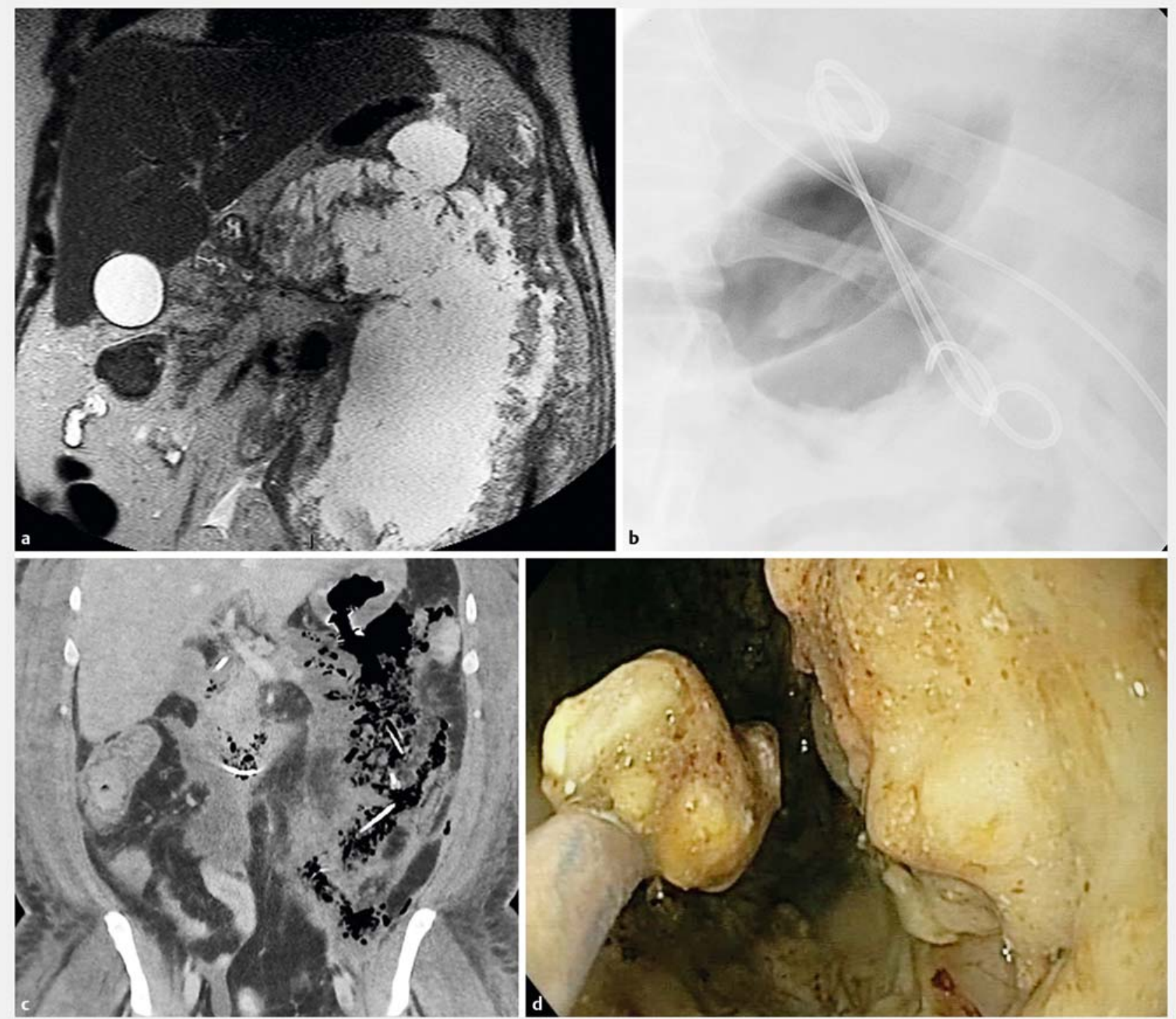

- Fig. 1 Management of a 35-year-old man with severe acute alcoholic pancreatitis and walled-off necrosis who was referred for management 30 days after his symptoms had begun. a Coronal magnetic resonance imaging T2 sequence showed a large, mostly fluid-filled walled-off necrosis, extending into the left iliac fossa. $\mathbf{b}$ Initial endoscopic ultrasound-guided drainage was performed with insertion of two double-pigtail stents and a nasocystic catheter for lavage. c Subsequently, after dilation of the orifice, a lumen-apposing metal stent was inserted and necrosectomy was performed. A coronal computed tomography image illustrates the stent with the nasocystic catheter passing through it. $\mathbf{d}$ Endoscopic image of the cavity, as seen during the necrosectomy sessions. A snare is used to retrieve the necrotic debris.

therefore other coexisting sources of infection need to be excluded [51].

The presence of gas in parenchymal or extrapancreatic necrosis on CT showed poor performance for assessing IPN in the abovementioned study (sensitivity $45.9 \%$; specificity $81.5 \%$; accuracy $50.5 \%$ ) [50]. Diffusion-weighted MRI can be used to detect IPN, but large studies are still lacking $[52,53]$.

The added value of fine needle aspiration (FNA) for diagnosing IPN is limited if clinical and/or imaging signs are taken into consideration [50]. Furthermore, there are a considerable number of false-negative $(20 \%-29 \%)$ and false-positive results $(4 \%-10 \%)[50,54]$.

\section{Conservative management of acute necrotizing pancreatitis}

\subsection{Fluid resuscitation}

\section{RECOMMENDATION}

ESGE recommends initial goal-directed intravenous fluid therapy with Ringer's lactate (e. g. $5-10 \mathrm{~mL} / \mathrm{kg} / \mathrm{h}$ ) at onset of the pancreatitis. Fluid requirements should be patient-tailored and reassessed at frequent intervals.

Strong recommendation, moderate quality evidence. 


\section{RECOMMENDATION}

ESGE suggests that fluid resuscitation assessment should be based on one or more of the following: (i) clinical targets (heart rate $<120$ beats/min, mean arterial pressure of $65-85 \mathrm{mmHg}$, urinary output $>0.5-1 \mathrm{~mL} / \mathrm{kg} / \mathrm{h}$ ), (ii) laboratory targets (hematocrit $<44 \%$, declining BUN levels, maintainence of normal serum creatinine levels during the first day of hospitalization) and, (iii) in the intensive care setting, invasive targets (central venous pressure of $8-12 \mathrm{mmHg}$, stroke volume variation, and intrathoracic blood volume determination).

Weak recommendation, moderate quality evidence.

\subsubsection{Type of fluid for initial resuscitation}

In a multicenter RCT (40 patients with severe acute pancreatitis), resuscitation with Ringer's lactate decreased the incidence of SIRS when compared to resuscitation with normal saline [55]. Intravenous hydration with Ringer's solution was found to be equivalent to nasojejunal hydration in a recent RCT (49 patients with severe acute pancreatitis) [56] (Table e3, available online in Supplementary materials).

\subsubsection{What is the optimal fluid infusion rate?}

Retrospective studies have demonstrated that aggressive early hydration in patients with severe acute pancreatitis is associated with decreased morbidity and mortality [57-60]. Three RCTs in endoscopic retrograde cholangiopancreatography (ERCP) patients showed that aggressive fluid administration reduced post-ERCP acute pancreatitis [61-63].

In contrast, three studies (2 RCTs) in patients with severe acute pancreatitis by Mao et al. supported that rapid hemodilution increased morbidity and mortality, although criticisms regarding design, randomization, and power were raised [6466]. Recently, Weitz et al. reported higher disease severity and more complications with aggressive hydration in patients with severe acute pancreatitis [67]. Patients with diminished cardiac reserve should be administered fluids cautiously, given their risk of pulmonary edema [68]. A study in 9489 patients with acute pancreatitis concluded that high volume fluids in the initial 48 hours were associated with increased mortality [69]. A prospective study demonstrated that administration of $>4.1 \mathrm{~L}$ of fluids during the initial 24 hours was linked to increased morbidity, while <3.1 L had no unfavorable consequences [70]. Obviously, selection biases (i.e. severe cases have worse outcomes despite vigorous management) should be considered when evaluating the results of non-randomized studies.

\subsubsection{What are the best non-invasive and invasive measures to assess appropriate fluid resuscitation in patients with acute pancreatitis?}

Apart from vital signs, serial measurements of hematocrit, BUN, and serum creatinine can serve as surrogate markers of hydration status and their use has been widely recommended $[24,31,71,72]$. Sole central venous pressure measurement is rather unreliable $[63,73]$ and inferior to assessment by techno- logically advanced intravascular monitoring systems, such as the continuous cardiac output monitoring system (PiCCO), in optimizing fluid management in acute pancreatitis [74, 75].

\subsection{Antibiotics}

\section{RECOMMENDATION}

ESGE recommends against antibiotic or probiotic prophylaxis of infectious complications in acute necrotizing pancreatitis.

Strong recommendation, high quality evidence.

\section{RECOMMENDATION}

ESGE recommends, in patients with suspected or proven infected necrosis, the use of antibiotics targeting gut-derived bacteria and adapted to culture and antibiogram results if available.

Strong recommendation, low quality evidence.

\subsubsection{Antibiotic prophylaxis in acute necrotizing pancreatitis}

Meta-analyses published since 2008 [76-83] have shown no benefit from the routine use of prophylactic antibiotics in patients with severe acute pancreatitis. Furthermore, prophylactic antibiotic use might increase the risk of intra-abdominal fungal infection [84, 85].

A meta-analysis (4 RCTs, 428 patients) showed no reduction in the risk of IPN or associated mortality with vs. without probiotic prophylaxis [86].

\subsubsection{Selection of antibiotics in patients with suspected infected pancreatic necrosis}

Intravenous antibiotics should be administered and further intervention considered once IPN is suspected. Antibiotics are useful in IPN to delay or even avoid intervention in mild cases $[3,33]$. Translocation of bacteria from the small bowel is thought to be the major source for infection of necrosis [87]. Empirically, antibiotics effective on gut-derived bacteria and known to penetrate into the pancreas (carbapenems, quinolone, metronidazole, and high dose cephalosporins) seem the most appropriate $[77,88,89]$. Once blood/FNA culture results have been obtained, antibiotic therapy should be adjusted accordingly.

\subsubsection{Duration of antibiotic therapy for infected pancreatic necrosis}

There are no data on the adequate duration of antibiotic therapy in patients with IPN (e.g. stopping rules for antibiotic administration) [77]. Antibiotics are commonly stopped 48 hours after the removal of the last drainage catheter, if all cultures remain negative. Improvement of clinical, biochemical, and ima- 
ging features may help guide the decision to stop antibiotic therapy [90-92].

\subsection{Nutrition}

\section{RECOMMENDATION}

ESGE recommends enteral tube feeding with polymeric enteral nutrition in all patients with predicted severe acute pancreatitis who cannot tolerate oral feeding after 72 hours.

Strong recommendation, high quality evidence.

\section{RECOMMENDATION}

ESGE suggests initiating enteral nutrition via a nasogastric tube, except in patients with hemodynamic instability, and to switch to the nasojejunal route in patients with digestive intolerance.

Weak recommendation, moderate quality evidence.

Parenteral nutrition should be commenced if there is persistent digestive intolerance or if the caloric goal is not met.

Weak recommendation, low quality evidence.

\subsubsection{Effects of enteral tube feeding in severe acute pancreatitis}

Gut-barrier dysfunction may occur in a significant percentage of patients with severe acute pancreatitis; it is thought to lead to bacterial translocation and infection of necrosis [93]. Enteral feeding is supposed to preserve the integrity of the gut mucosa, stimulate intestinal motility, prevent bacterial overgrowth, and increase the splanchnic blood flow [94].

Twelve RCTs and eight meta-analyses have been performed regarding enteral and parenteral nutrition in acute pancreatitis [95]. The three most recent meta-analyses showed that, in patients with predicted severe acute pancreatitis, enteral nutrition as compared to parenteral nutrition decreases systemic infections, multiple-organ failure, need for surgical intervention, and mortality [96-98]. However, the RCTs have several limitations such as heterogeneity in the severity of acute pancreatitis and in the delay before nutritional intervention; other limitations include small sample sizes, poor glycemic control in the parenteral groups in the older studies, and suboptimal calorie goal attainment [95].

\subsubsection{Timing of enteral tube feeding \\ in severe acute pancreatitis}

Previously, non-randomized studies involving patients with predicted severe acute pancreatitis, including two systematic reviews (775 and 451 patients) $[99,100]$, have shown that nasoenteric tube feeding started within 48 hours after admission, as compared with after 48 hours, significantly reduces the rate of major infection and in some studies even reduces mortality
[101, 102]. Nevertheless, a multicenter RCT (208 patients with predicted severe acute pancreatitis) found no difference in the rate of major infection or death between early nasoenteric tube feeding, started within 24 hours after admission, and an oral diet initiated 72 hours after admission [103].

The abovementioned trial challenges the gut mucosa-preserving effect of early enteral nutrition during acute pancreatitis and is in line with the "permissive underfeeding" concept [104]. A second RCT (214 patients with acute pancreatitis) confirmed these results, showing no significant reduction in persistent organ failure and mortality in patients receiving early enteral nutrition compared with patients receiving no nutritional support [105].

\subsubsection{Type of enteral nutrition}

Two meta-analyses, involving previous RCTs comparing enteral to parenteral nutrition, focused on the effect of different formulations by means of secondary analysis [106, 107]. Both reviews found no differences between polymeric vs. (semi)elemental nutrition, in terms of feeding intolerance, infectious complications, or death.

\subsubsection{Should enteral nutrition be administered via the nasojejunal or nasogastric route?}

Four studies (3 RCTs) compared nasojejunal with nasogastric feeding in patients with severe acute pancreatitis [108-111] (Table e4, available online in Supplementary material), and an RCT compared nasogastric tube feeding vs. parenteral nutrition [112]. Based on these trials, four meta-analyses found no differences between nasogastric and nasojejunal enteral feeding regarding tolerance and mortality [113-116]. One study reported a higher pulmonary complication rate in patients receiving nasogastric enteral feeding [111]. Limitations of the abovementioned RCTs include heterogeneity with regard to timing and severity of acute pancreatitis, exclusion of patients with hemodynamic instability and likely very severe disease, and absence of routine confirmation of the nutrition tube position [95].

\subsection{Specific treatment of biliary acute pancreatitis}

\section{RECOMMENDATION}

ESGE recommends urgent ( $\leq 24$ hours) ERCP and biliary drainage in patients with acute biliary pancreatitis combined with cholangitis.

Strong recommendation, high quality of evidence. ERCP should be performed within 72 hours in patients with ongoing biliary obstruction.

Weak recommendation, moderate quality evidence. It should not be performed in patients with acute biliary pancreatitis and neither cholangitis or ongoing bile duct obstruction.

Weak recommendation, moderate quality evidence. 


\subsubsection{What are the indications for early ERCP and} sphincterotomy in the setting of biliary acute pancreatitis?

Based on the initial RCTs, ERCP was shown to be effective in decreasing the incidence of complications in biliary acute pancreatitis $[117,118]$. These trials included patients with cholangitis, who may benefit more than those without cholangitis. For this reason, a multicenter RCT excluding patients with cholangitis was performed; it failed to show a benefit of early ERCP in the community hospital setting [119]. Three other RCTs also failed to show a benefit from ERCP in this group of patients [120 - 122] (Table e5, available online in Supplementary materials).

The Cochrane meta-analysis of these trials showed no difference in outcomes with vs. without ERCP, independently of acute pancreatitis severity and ERCP timing, except for patients with cholangitis [123]. A trend toward a decreased complication rate was observed for patients without cholangitis but with ongoing biliary obstruction (common bile duct stone and/or abnormal bilirubin and/or common bile duct dilatation). However, significant group heterogeneity, the lack of systematic sphincterotomy in the absence of common bile duct stones, and a type II statistical error could be potential biases.

\subsubsection{Optimal timing for ERCP in the setting of biliary acute pancreatitis with and without cholangitis}

No study has been specifically designed to assess the timing of ERCP in biliary acute pancreatitis. The available RCTs that have evaluated ERCP in acute pancreatitis have used variable time frames, from $<24$ hours [118] to 72 hours after the beginning of the symptoms [119], or after admission [117, 120,121] (Table e5, available online in Supplementary materials).

In the 2012 Cochrane systematic review, there were no significant differences in mortality between the early ERCP strategy and the early conservative management strategy regardless of time to ERCP (within 24 hours vs. within 72 hours of admission) [123]. The International Association of Pancreatology (IAP)/American Pancreatic Association (APA) guideline states that urgent ERCP ( $<24$ hours) should be performed in patients with biliary pancreatitis and cholangitis [1].

\section{Invasive (radiological, endoscopic, or surgical) interventions}

\section{RECOMMENDATION}

ESGE recommends invasive intervention for patients with acute necrotizing pancreatitis and clinically suspected or proven infected necrosis.

Strong recommendation, low quality evidence.
RECOMMENDATION

ESGE suggests considering an invasive intervention in patients with acute necrotizing pancreatitis and persistent organ failure or "failure to thrive" for several weeks. Weak recommendation, low quality evidence.

\section{RECOMMENDATION}

ESGE suggests considering an invasive intervention after failure of conservative treatment in patients with sterile necrosis and adjacent organ compression or persistent pain late in the course of the disease.

Weak recommendation, low quality evidence.

\section{RECOMMENDATION}

ESGE suggests that the management plan should be individualized, considering all of the available data (clinical, radiological, and laboratory) and taking into account the available expertise.

Weak recommendation, moderate quality evidence.

Indications for intervention (radiological, endoscopic, or surgical) in ANP are [1]:

- Proven IPN.

- Clinically suspected IPN: in the absence of documented IPN, ongoing organ failure or persisting unwellness ("failure to thrive") for several weeks after the onset of acute pancreatitis, despite optimal medical therapy, preferably when the necrosis has become walled off, as a retrospective study (164 patients) found that $42 \%$ of these patients had IPN [54].

- Organ compression, in the absence of IPN, including gastric outlet syndrome, intestinal, or biliary obstruction, and pain due to mass effect from large WON (intervention should preferably be performed $>4-8$ weeks after the onset of acute pancreatitis) $[124,125]$. Secondary infection is a major concern regarding these indications.

- Abdominal compartment syndrome: this situation is less common but it may require radiological or surgical decompression early in the course of acute pancreatitis. Nevertheless, it is advised to refrain from exploring the lesser sac or performing a necrosectomy at the same time, because there is a risk of bleeding and of introducing infection into sterile necrosis [126, 127].

Data from small cohort studies as well as a recent meta-analysis, including studies with significant heterogeneity, suggest that a proportion of patients with IPN (6/42; 14\%) [128] can be treated with antibiotics alone [23,128-131] (Table e6, available online in Supplementary materials). However, the exact subgroup of these clinically stable patients has not been clearly defined. Furthermore, conservative treatment included 
percutaneous catheter drainage (PCD) in some studies, making it difficult to identify a group receiving only antibiotics [23, 131].

\section{Technical modalities of invasive interventions}

\subsection{Radiology}

\subsubsection{Technique of percutaneous catheter drainage}

In a systematic review including 10 retrospective series and one RCT with a total of 384 patients undergoing PCD, the procedures were performed under CT (8 studies) or ultrasound guidance (2 studies), where this was reported [132]. Ultrasound guidance in combination with fluoroscopy is often preferred during the initial PCD procedure. Real-time imaging during puncture can prevent puncture of interpositioned bowel loops. After initial puncture, guidewires can be steered under fluoroscopic guidance. If the necrotic collections cannot be visualized with ultrasound because of limited liquid content, a CT-guided drainage can be performed. If possible, a retroperitoneal access route should be chosen, between the spleen, descending colon, and left renal upper pole for left-sided drainage, or between the ascending colon and upper pole of the right kidney for right-sided drainage.

No comparative data have been published regarding the use of sedation, local, or general anesthesia. PCD is usually performed with local infiltration of lidocaine combined with moderate/conscious sedation with midazolam and fentanyl, while deep propofol sedation is given if multiple large-bore catheters are to be placed.

In the aforementioned systematic review, drain diameter varied from 8 to $28 \mathrm{Fr}$ [132]. There is no comparative trial regarding catheter diameter, but large-bore catheters (>14 Fr) seem to obstruct less frequently [132]. Drains may need upgrading to a larger diameter or replacement in about half of the patients [133]. Regular silicone pigtail drains are used, placed according to the Seldinger or the tandem trocar technique [132].

\subsubsection{Use of percutaneous catheter drainage (drainage and flushing)}

Flushing of the catheters with saline can be performed to improve drainage efficacy and avoid catheter obstruction. In the aforementioned systematic review, drains were flushed with saline every 8 hours [132]. Where there is inadequate drainage of necrotic material, additional flushing catheters may be placed to create a continuous flushing/drainage system.

\subsection{Endoscopy}

Various endoscopic techniques are used to treat WON; all of these include transmural access to the cavity, using either an echoendoscope (EUS-guided drainage) or, for bulging collections, a standard endoscope (conventional transmural drainage); the former approach has nowadays largely replaced conventional transmural drainage (“blind” access) [134].
The available endoscopic approaches include: (i) endoscopic drainage (placement of a transmural drain such as double-pigtail or metal stents into the cavity, performed through a single or several access sites, the latter technique being termed the multiple transluminal gateway technique [MTGT]) [135]; (ii) transluminal endoscopic necrosectomy (removal of necrotic debris using devices such as a stone-retrieval basket introduced from the digestive lumen into the cavity), and (iii) direct transluminal endoscopic necrosectomy (DEN; insertion of the endoscope into the cavity to remove necrotic debris) $[136,137]$. Endoscopic drainage has been combined with PCD in the "dual-modality drainage technique" [138].

Furthermore, an intervention is said to be primary if it is the first intervention performed to access WON and secondary if it is preceded by another intervention (e.g. endoscopic necrosectomy following PCD).

\subsubsection{What is the preferred modality for establishing transmural access (EUS-guided vs. non-EUS)?}

\section{RECOMMENDATION}

ESGE recommends that EUS-guided access should be preferred over conventional transmural drainage for initial endoscopic transmural drainage.

Strong recommendation, moderate quality evidence.

The main advantage of EUS-guided puncture is to allow treatment of PFCs that do not bulge into the gastrointestinal lumen [139]. A prospective comparative study showed no differences between conventional $(n=53)$ and EUS-guided $(n=46)$ drainage for patients with pseudocysts regarding success rates in both the short ( $94 \%$ vs. $93 \%$ ) and long term ( $91 \%$ vs. $84 \%$ ), nor in complications rates (18\% vs. 19\%) [140]. Nevertheless, only patients with bulging PFCs and without obvious portal hypertension were drained by the conventional method [140].

Later on, two RCTs confirmed the superiority of EUS-guided access regarding technical success ( $100 \%$ vs. $33 \%$ and $94 \%$ vs. $72 \%)[141,142]$. In patients where conventional drainage failed because of non-bulging PFCs, EUS-guided access succeeded. Both trials included pancreatic pseudocysts only, but results can be generalized to patients with WONs (Table e7, available online in Supplementary materials).

\subsubsection{Is there a benefit of using a forward-viewing vs. a standard EUS scope in some settings?}

The feasibility of endoscopic drainage of PFCs using forwardviewing EUS has been described in a few small retrospective case series $[143,144]$. Only one RCT including PFCs requiring transgastric drainage is available. This study did not show a difference in technical success or ease of the procedure when using the forward-viewing EUS scope compared with the standard oblique-viewing EUS scope [145]. 


\subsubsection{What are the optimal access dilation modalities?}

\section{RECOMMENDATION}

ESGE suggests performing progressive balloon dilation of the cystoenterostomy fistula starting at $6-8 \mathrm{~mm}$, potentially increasing during the days following endoscopic transmural drainage, with stent placement, if direct endoscopic necrosectomy is required.

Weak recommendation, low quality evidence.

After endoscopic puncture of WON, balloon dilation (6-8 $\mathrm{mm}$ ) of the access site is performed over a 0.035 -inch guidewire to create a fistula between the digestive lumen and WON in order to facilitate stent insertion [146]. Puncture with an electrocautery needle followed by dilation of the cystogastrostomy or cystoduodenostomy with a cautery-tip catheter can also be performed over the guidewire, before further balloon dilation and stent insertion [147].

Where DEN is undertaken, a progressive dilation with a controlled radial expansion balloon of the WON entry is performed, usually after removing the double-pigtail stent(s), a few days after the initial endoscopic drainage [148, 149]. DEN performed during the initial WON endoscopic access in a singlestep procedure has also been described [150 - 152].

\subsubsection{Types of stent for maintaining transmural access}

\section{RECOMMENDATION}

ESGE suggests either plastic stents or lumen-apposing metal stents for initial endoscopic transmural drainage; however, long-term data on lumen-apposing metal stents are still sparse.

Weak recommendation, moderate quality evidence.

After transmural access of WON has been established, maintainence of a large open access is required to allow the evacuation of debris, pus, and necrotic tissue, and eventually to allow repeated DEN when needed [153]. Two options are available: multiple plastic double-pigtail stents or self-expandable metal stents (SEMSs). Plastic stents are usually double-pigtail stents in order to avoid migration, with various diameters (7 Fr$10 \mathrm{Fr}$ ). SEMSs are either fully covered biliary metal stents (FCSEMSs), lumen-apposing metal stents (LAMSs; Axios stent, Boston Scientific, Natick, Massachusetts, USA; Nagi stent or Spaxus stent, Taewoong, Seoul, South Korea), or esophageal SEMSs ( Fig. 1 b,c).

A systematic review (17 studies, 881 patients, 183 with WON) showed no differences regarding treatment success for drainage by plastic stents or metal stents in PFCs, including pancreatic pseudocysts and WONs [154]. In addition, in a retrospective comparative study including 70 patients with WON, there was no difference between plastic stents ( $n=27$ patients) and SEMSs (mix of LAMS and FC-SEMS; $n=43$ ), except for a shorter procedure time for SEMSs (28.8 vs. 42.6 minutes; $P<0.001$ ) [155]. On the other hand, another recent retrospective comparative study, including 133 patients with WON treated with multiple plastic stents $(n=61)$ or LAMSs $(n=72)$, showed a superior clinical success rate for LAMSs ( $94 \%$ vs. 74\%; $P<0.05$ ) [156] (Table e8, available online in Supplementary materials).

A US single-center RCT comparing LAMSs vs. multiple plastic stents for patients with WON is ongoing but interim analysis has revealed an important rate of delayed stent-related adverse effects in the LAMS group (6/12; $50 \%)$, consisting of bleeding and embedded LAMSs [157]. The authors have since changed the study protocol and underline the need for CT imaging to exclude vascular complications, such as pseudoaneurysms, and retrieval of the LAMS within 4 weeks.

\subsubsection{What type of scope is preferred for use during subsequent necrosectomy sessions?}

\section{RECOMMENDATION}

ESGE suggests performing subsequent necrosectomy with a therapeutic gastroscope.

Weak recommendation, low quality evidence.

There are no data comparing types of scopes used for subsequent necrosectomy. Most often the use of a gastroscope is stated in the literature for this procedure, without however differentiating between double-channel, pediatric, standard, or therapeutic gastroscopes. From a technical perspective, a scope with a larger working channel that facilitates evacuation of fluids and entry of equipment to be used for necrosectomy is preferred [149,152,158-164] (Table e9, available online in Supplementary materials).

Although not developed in the currently available literature, the position of the initial puncture is also important when DEN is foreseen. Access that is too proximal (i. e. fundus or cardia) or too distal (i. e. from the antrum) may compromise the direct introduction of a gastroscope into the cavity and render its manipulation more difficult.

\subsubsection{What are the modalities of use of nasocystic catheters} (duration, type, frequency of flushing, and removal)?

It is necessary to distinguish between insertion of a nasocystic catheter with irrigation during the access phase of the WON, between each necrosectomy session, and finally during a session of necrosectomy to facilitate debridement.

During the access phase, the nasocystic catheter can be placed in parallel to the plastic stents $[147,149,151,160-$ $163,165,166]$ or through the deployed metal stent $[159,164]$. The most frequently described protocol involves the constant instillation of normal saline solution via a 5- to 7-Fr catheter at a daily volume of $500-1000 \mathrm{~mL}[160,161,165]$. Only two studies have reported their experience of sequential irrigation with a flushing volume ranging from 50 to $500 \mathrm{~mL}$ three to six times per day during the access phase and between each necrosectomy session $[160,162]$. This protocol was associated with a 
clinical success of $89 \%$ after a median of four endoscopic procedures in a retrospective analysis of 81 patients [160].

Some authors suggest antibiotic irrigation according to the microbiological findings is an alternative to the use of normal saline $[150,158,160]$. Endoscopic lavage through the working channel of the endoscope is also proposed during the necrosectomy session, occasionally with a large volume of warmed antibiotic (1-2L of bacitracin-saline, 25000 Units/L) or with $100-300 \mathrm{~mL}$ of $0.1 \%-0.3 \%$ hydrogen peroxide directly sprayed over the necrotic material $[150,152,161]$.

No prospective randomized trials exist that have assessed the duration, type, and volume of irrigation. Furthermore, no significant difference in terms of clinical success was found with or without nasocystic tube placement in a large multicenter study (90.9\% vs. 95.6\%; $P=0.59$ ) [167]. High clinical resolution $(86 \%-94 \%)$ was also reported by authors without any instillation protocol or when only performed during the debridement phase [150,164] (Table e9, available online in Supplementary materials).

Finally, nasocystic irrigation seems to be safe. With the exception of a peritoneal perforation during a forced irrigation with $1000 \mathrm{~mL}$ saline that led to subsequent organ failure and death, no severe adverse events have been reported [160].

\subsubsection{What different necrosectomy devices are available and how do they compare?}

Endoscopic necrosectomy is performed by a combination of sucking debris through the working channel, removing necrotic material with a removal device, and applying irrigation. No endoscopic accessory is specifically dedicated to the removal of pancreatic necrosis and/or infected debris. A variety of auxiliary instruments have been used for endoscopic necrosectomy, including polypectomy snares, Dormia and other stoneremoval baskets, balloons, nets, tripod retrieval forceps, or grasping/rat-tooth/pelican forceps [91, 136, 151, 168-171].

Any device needs to balance the efficacy of removing debris with safety (i.e. the avoidance of injury to vital tissues and retroperitoneal vessels). Comparative trials of endoscopic necrosectomy devices do not exist. Snares and baskets might be preferred for the primary attempt to remove pancreatic necrosis as they are safe and quite effective ( $\mathbf{F i g} \mathbf{1 d}$ ).

\subsubsection{What other auxiliary methods are available?}

\section{RECOMMENDATION}

ESGE suggests restraint regarding the use of high-flow water-jet systems, hydrogen peroxide, or vacuum-assisted closure systems to facilitate debridement of necrosis in walled-off necrosis because of insufficient evidence. Weak recommendation, low quality evidence.

Unconventional methods, such as using a high-flow waterjet system $[159,172-175]$, hydrogen peroxide $(0.1 \%-3 \%)$ application [161, 176, 177], and a vacuum-assisted closure system [178-180], to facilitate debridement of necrosis in WON have been described. However, none of these case series included the minimal required number of patients to qualify for inclusion in the current Guideline.

\subsubsection{Use of $\mathrm{CO}_{2}$ vs. air for insufflation}

\section{RECOMMENDATION}

ESGE recommends exclusive use of $\mathrm{CO}_{2}$ instead of air for insufflation during necrosectomy to reduce the risk of gas embolism.

Strong recommendation, low quality evidence.

$\mathrm{CO}_{2}$ is a gas that is rapidly absorbed and highly soluble in water and/or blood. For endoscopic interventions, $\mathrm{CO}_{2}$ might reduce the risk of air embolism, which is a rare but well-known severe event that occurs when air enters the systemic venous circulation. The risk of gas embolism can be significantly reduced by insufflating $\mathrm{CO}_{2}$ instead of air, because of the higher capacity of blood to absorb $\mathrm{CO}_{2}$ compared with air or other gases. When air insufflation was used during endoscopic necrosectomy, suspected or likely air embolism occurred in $0.9 \%-2 \%$ of procedures according to published series [149, 151, 163, 168]. Air embolism has not been documented in later reports after the introduction of $\mathrm{CO}_{2}$ insufflation. Nevertheless, gas insufflation should be minimized during necrosectomy to maintain minimal gas pressure within the retroperitoneum.

\subsubsection{Association of transpapillary pancreatic drainage with transmural drainage of WON}

\section{RECOMMENDATION}

ESGE suggests that, in the case of endoscopic transmural drainage of walled-off necrosis, transpapillary drainage of the main pancreatic duct should not be routinely attempted.

Weak recommendation, low quality evidence.

One retrospective study suggested a better outcome for combined transpapillary and transmural PFC drainage where there was partial MPD disruption [181]; another showed no difference [182]. Both studies included only a few patients with WON. A third study reported a negative association between an attempt at transpapillary drainage being made and longterm radiological resolution [183] (Table e10, available online in Supplementary materials). 


\subsubsection{Technique and indications for the multiple} transluminal gateway technique

\section{RECOMMENDATION}

ESGE suggests drainage of walled-off necrosis using the single transluminal gateway technique; the multiple transluminal gateway technique should be considered in patients with either multiple or large $(>12 \mathrm{~cm})$ walled-off necrosis, or in the case of suboptimal response to single transluminal gateway drainage.

Weak recommendation, low quality evidence.

Three retrospective case series compared MTGT (with up to three puncture sites) with single-access endoscopic drainage for WON $[135,165,184]$. In total, 41 of 211 patients (19\%) received MTGT and the two series that reported the results separately for each technique found that clinical success was seen more frequently after MTGT $[135,182]$. The authors who described the MTGT initially used it when there was minimal drainage after initial puncture of WON [135]. They then used a step-up algorithm where MTGT was performed for WON $>12 \mathrm{~cm}$ in size and for unilocular WON $\leq 12 \mathrm{~cm}$ that had responded suboptimally to single transluminal drainage [134] (Table e11, available online in Supplementary materials). Furthermore, additional access is sometimes necessary when the first access is in such a position that it does not allow easy scope introduction into the cavity for DEN.

\subsubsection{How many sessions are required and how long is the length of hospitalization?}

For endoscopic drainage, a comparative series reported that $25 \%$ and $50 \%$ of patients treated according to the single and multiple transluminal gateway techniques, respectively, required endoscopic re-intervention (median 1.3 and 1.5 sessions, respectively) [135]. For endoscopic necrosectomy, the mean number of sessions varied between 1 and 15 (weighted mean 4) in a meta-analysis [185]. For dual-modality drainage, a mean of 1.9 endoscopic sessions, plus an unspecified number of EUS sessions and a mean of 6.2 PCD studies were performed [186].

In two RCTs, the median hospital stays after randomization to endoscopic necrosectomy were 45 days [91] and 39 days [187]. Following dual-modality drainage, a mean hospitalization of 24 days was reported [186].

\subsection{Surgery}

The surgical approach to infected necrotizing pancreatitis has evolved: the traditional procedure of choice, direct open necrosectomy, has been replaced by a step-up approach in which PCD of the retroperitoneum is first performed, preferably via the left flank. Where insufficient clinical improvement occurs despite adequate drainage of all (peri)pancreatic necrotic collections ( $45 \%-65 \%$ of patients), minimally invasive surgical necrosectomy is performed $[132,133]$.
Two techniques are used: in sinus tract endoscopy, a flexible or rigid endoscope is introduced into the PCD tract following dilation and the solid debris is removed using grasping forceps [188]; in video-assisted retroperitoneal debridement (VARD), sinus tract endoscopy is combined with a $5-\mathrm{cm}$ lumbotomy that makes the procedure easier to conduct and allows for the removal of larger pieces of necrotic material [189]. Following sinus tract endoscopy or VARD, a continuous lavage system is maintained until the lavage fluid becomes clear or until the next procedure. The drains stay in place for several weeks until the drainage product becomes clear and there is no evidence of a pancreaticocutaneous fistula.

\section{Outcome of invasive interventions}

\subsection{Drainage interventions}

5.1.1 How do percutaneous and combined percutaneous and endoscopic drainage compare in terms of success, duration of hospitalization, number of interventions, and number of diagnostic imaging studies?

\section{RECOMMENDATION}

ESGE suggests considering concurrent endoscopic transmural drainage and percutaneous drainage in patients with walled-off necrosis with extension to the pelvic paracolic gutters.

Weak recommendation, low quality evidence.

A systematic review focusing on PCD as a primary treatment for ANP, including 10 retrospective series and one RCT (total 384 patients), concluded that no additional surgical necrosectomy was required in $55.7 \%$ of patients (214/384) [132]. Similarly, a systematic review evaluating conservative treatment (including antibiotics and PCD if required) reported a successful outcome in $64 \%$ of patients; a separate analysis including four studies that reported outcomes of non-consecutive patients with IPN following PCD reported similar results $(50 \%$ had a successful outcome, mortality was $18 \%$, and $38 \%$ required surgery) [190].

Three recent retrospective studies from a single center reported on the use of dual-modality drainage to treat WON $[138,186,191]$. A potential advantage of dual-modality drainage is the absence of a pancreaticocutaneous fistula (0 of 103 patients in the most recent study) [191]. One of these studies (94 patients) was comparative [186]; it showed that, compared with PCD alone, dual-modality drainage was associated with fewer drain studies (6.2 vs. 13.0), endoscopic procedures (1.9 vs. 2.6), and CT scans (7.8 vs. 14.0), shorter hospitalization (24 vs. 54 days), and fewer pseudoaneurysm bleeds ( $0 \%$ vs. $11 \%$ ). Overall mortality and the requirement for surgery were similar in both groups. Of note, patients in the dual-modality group presented less frequently with paracolic gutter extension of the WON (39\% vs. $60 \%$ ) and had a longer delay between acute pancreatitis and drainage (53 vs. 34 days), suggesting selection bias. 
In the published series on dual-modality drainage the procedures were performed on the same day [191].

\subsubsection{Factors predictive of the need for necrosectomy}

A retrospective analysis (53 patients) reported that larger size of WON (median diameter $18 \mathrm{~cm}[12-21 \mathrm{~cm}]$ vs. $14 \mathrm{~cm} \mathrm{[3-}$ $46 \mathrm{~cm}$ ]; $P=0.01$ ), extension of WON to the paracolic gutters, and preexisting diabetes were associated with the need for surgical interventions after initial endoscopic treatment [192]. In a post-hoc analysis of a prospective multicenter database (639 patients with ANP), the need for intervention was lower in patients with only EXPN than in patients with parenchymal necrosis with or without EXPN ( $18 \%$ vs. $57 \%$; $P<0.001)$ [22]. In a retrospective study (43 patients with WON), the extent of the necrosis $(r=0.703 ; P<0.001)$, increasing size of the WON $(r=$ $0.320 ; P=0.047)$, and the amount of solid debris $(r=0.800 ; P<$ 0.001 ) measured by EUS correlated with the need for more aggressive therapeutic methods [48].

In a prospective cohort of 109 patients with acute pancreatitis (including 80 with ANP and 39 with WON) who underwent CE-CT within the first 5 to 7 days of onset, an admission BUN of $\geq 20 \mathrm{mg} / \mathrm{dL}$ and a baseline necrotic collection $>6 \mathrm{~cm}$ were associated with the development of WON, with ORs of 10.96 (95\% confidence interval $[\mathrm{Cl}] 2.57-46.73 ; P=0.001)$ and 14.57 (Cl 1.60-132.35; $P=0.017$ ), respectively [193]. In a post-hoc analysis of 130 prospectively included patients who underwent catheter drainage (113 percutaneously, 17 endoscopically) for suspected IPN, the percentage of pancreatic necrosis ( $<30 \%$, $30 \%-50 \%$, and $>50 \%$; OR 0.44 ; Cl $0.23-0.83 ; P=0.01$ ), and heterogeneous collection (OR $0.19 ; \mathrm{Cl} 0.06-0.61 ; P=0.005$ ) were the two imaging factors shown to be associated with a lower rate of success (success being defined as survival without necrosectomy) [194] (Table e12, available online in Supplementary materials).

Two other studies identified the factors that predicted failure of catheter drainage and the need for subsequent surgery: persistent organ failure and multiple-organ failure, higher CRP levels, and extent of necrosis (> $50 \%$ of the pancreas) $[190,195]$.

\subsection{Various approaches to necrosectomy}

\subsubsection{How do the various surgical approaches (open surgery, laparoscopy, and minimally invasive surgery) compare in terms of success, morbidity/mortality, cost- effectiveness, hospital stay duration, and technical knowledge requirement?}

\section{RECOMMENDATION}

ESGE suggests minimally invasive surgery should be preferred to open surgery.

Weak recommendation, moderate quality evidence.

A meta-analysis (4 studies including one RCT, 336 patients) found that minimally invasive surgery was better than open surgery in terms of multiple-organ failure, incisional hernias, enterocutaneous fistula or perforation of visceral organs, and pancreatic insufficiency, but the high heterogeneity of the data did not permit a definitive conclusion to be drawn [196].

\subsubsection{How does endoscopic necrosectomy compare with other approaches in terms of success, morbidity, mortality, and cost-effectiveness?}

\section{RECOMMENDATION}

ESGE suggests that, in the absence of improvement following endoscopic transmural drainage of walled-off necrosis, endoscopic necrosectomy or minimally invasive surgery (if percutaneous drainage has already been performed) is to be preferred over open surgery as the next therapeutic step, taking into account the location of the walled-off necrosis and local expertise.

Weak recommendation, low quality evidence.

Endoscopic necrosectomy was examined in three meta-analyses $[153,197,198]$; the largest one included 455 patients and found a success rate of $81 \%$ with endoscopy alone and a complication rate of $36 \%$ [153].

There are no comparative studies of early (during initial access) vs. delayed DEN. Possible clinical improvement with WON drainage alone (in a recent RCT, drainage was sufficient in $41 \%$ ) [187] supports delaying DEN for a few days after endoscopic drainage $[91,198]$.

Endoscopic necrosectomy has been compared with various interventions.

- Compared with VARD, endoscopic necrosectomy was associated with a better outcome in a small RCT including 22 patients with IPN, as assessed by a composite endpoint including major morbidity or mortality ( $80 \%$ vs. $20 \%$ ) [91]. Moreover, endoscopic necrosectomy was associated with less major morbidity (new onset multiple-organ failure $0 \%$ vs. $50 \% ; P=0.03)$ and a nonsignificant difference in mortality (10\% vs. $40 \%)$ in this trial [91]. Nevertheless, a second larger trial (98 patients) comparing endoscopic (drainage and necrosectomy if required) and surgical (PCD and VARD if required) step-up did not show superiority of endoscopic necrosectomy with regard to major complications and death, but there were fewer occurrences of fistulas and a shorter length of stay [187] (Table e13, available online in Supplementary materials).

- Compared with PCD (matched cohort study; n=24), endoscopic necrosectomy was associated with more frequent clinical resolution ( $92 \%$ vs. $25 \%$ ), shorter length of stay, and lower healthcare utilization [152].

- Compared with minimally invasive retroperitoneal necrosectomy (retrospective study; $n=32$ ), endoscopic necrosectomy was associated with a similar success rate but fewer interventions and a shorter length of stay ( 21 vs. 63 days) [199] (Table e14, available online in Supplementary materials).

- Compared with open necrosectomy, endoscopic necrosectomy was associated with similar success rates but fewer 
complications ( $27 \%$ vs. $86 \%$ and $44 \%$ vs. $90 \%$ ) and shorter length of stay (32 vs. 74 days and 21 vs. 52 days) [199, 200]. In both studies, mortality was also lower with endoscopic necrosectomy ( $0 \%$ vs. $14 \%$ and $6 \%$ vs. $63 \%$ ) [199, 200].

\subsection{Step-up approaches}

\section{RECOMMENDATION}

ESGE recommends performing endoscopic or percutaneous drainage of (suspected) infected walled-off necrosis as the first interventional method, taking into account the location of the walled-off necrosis and local expertise. Strong recommendation, moderate quality evidence.

\section{RECOMMENDATION}

ESGE suggests delaying the first intervention for 4 weeks if tolerated by the patient.

Weak recommendation, low quality evidence.

\subsubsection{How do step-up and open necrosectomy compare} in terms of death or major morbidity, new onset multipleorgan failure, and long-term morbidity?

A Cochrane meta-analysis (8 RCTs, 306 patients) found that: (i) compared with open necrosectomy, the minimally invasive step-up approach was better in terms of both overall and serious adverse events and mean costs; and (ii) compared with the video-assisted (VARD) minimally invasive step-up approach, the endoscopic-assisted (DEN) minimally invasive step-up approach was better in terms of adverse events, but required more procedures (median difference 2) [201]. It also concluded that the differences in short-term mortality were imprecise for all comparisons.

One of the RCTs included in the meta-analysis showed, in 88 patients, that the step-up strategy was superior to open necrosectomy in terms of new-onset multiple-organ failure (12\% vs. $40 \%$ ) and long-term morbidity (new-onset pancreatic insufficiency), but not in terms of mortality (19\% vs. 16\%) [133]. In this RCT, the step-up approach used PCD or endoscopic (2 patients only) drainage followed by VARD if necessary. A recent RCT revealed that a step-up approach using transmural endoscopic drainage followed by DEN if necessary was comparable to the PCD/VARD step-up approach with regard to major complications and death. However, the rate of pancreatic fistula formation ( $5 \%$ vs. $32 \%$ ), length of stay, and costs were significantly reduced in the endoscopic group [187].

\subsection{Complications}

\subsubsection{What are the adverse effects of endoscopic} necrosectomy and how often do they occur?

Based on a systematic review including 13 retrospective cohort series $(n=455)$ and the aforementioned RCT $(n=98)$, the overall complication rate was $36 \%$ [153]. Bleeding was the most common complication with an incidence of $18 \%$. Perforation (excluding gastric/duodenal perforation) occurred in $4 \%$ of patients, and a pancreatic fistula developed in $5 \%$.

\section{Late outcomes of invasive interventions}

\subsection{When and how should follow-up imaging be performed after invasive procedures for WON?}

\section{RECOMMENDATION}

ESGE suggests deciding on follow-up imaging based on clinical findings or when invasive treatment is contemplated, in which case contrast-enhanced $\mathrm{CT}$ is the imaging method of choice.

Weak recommendation, low quality evidence.

Though evidence relating to the specific timing of follow-up imaging is lacking, it appears most feasible to conduct these follow-up studies based on relevant clinical findings or when invasive treatment is contemplated, instead of offering routine follow-up [1]. Relevant clinical findings include: sudden-onset or increase of abdominal pain, organ failure, signs of sepsis, and other signs of local complications (e. g. sudden drop of hemoglobin).

CE-CT is considered the imaging method of choice for the assessment of evolving local complications, guidance on when and how to employ invasive treatment, and monitoring response to treatment, as well as for successful placement of stents and drains.

\subsection{When should percutaneous drains be removed?}

\section{RECOMMENDATION}

ESGE suggests removing percutaneous drains when the effluent is clear and production is less than $50 \mathrm{~mL}$ per 24 hours, with no evidence of a pancreaticocutaneous fistula.

Weak recommendation, very low quality evidence.

There are no studies available regarding this subject.

\subsection{When should transluminal stents be removed?}

\section{RECOMMENDATION}

ESGE recommends retrieval of lumen-apposing metal stents within 4 weeks to prevent stent-related adverse effects, and long-term indwelling of double-pigtail plastic stents in patients with disconnected pancreatic duct syndrome.

Strong recommendation, low quality evidence.

Regarding drainage of WON with plastic stents and longterm indwelling of stents in patients with disconnected pancreatic duct syndrome (DPDS), data from retrospective series have 
indicated a low rate of recurrence, as well as a low rate of spontaneous stent migration [202,203]. Regarding complications, data were however not homogeneous. In one series, two serious adverse events occurred due to small-bowel obstruction as a consequence of spontaneous stent migration [203]. The available RCT included patients with mainly pseudocysts and with MPD rupture in half of the studied population. This study revealed a significant reduction in recurrence in those in whom the stent was left in situ ( $0 \%$ vs. $38 \%$ recurrence), with MPD rupture seeming to predispose to recurrent pseudocysts in patients having the stent removed [204]. Infectious complications due to permanent stent indwelling did not occur in any of the aforementioned series.

Regarding LAMSs, although a study reported that stents were removed after a median of 32 days (range $2-178$ ), with no LAMS-related adverse effects [205], an interim analysis of an ongoing RCT revealed a worrisome rate of LAMS-related adverse effects $(50 \% ; 6 / 12)$ in the group of patients who had undergone LAMS insertion [157]; this incited investigators to modify the protocol so that LAMSs were retrieved within 4 weeks. A consequence of this is that, in patients with suspected DPDS, LAMSs should be replaced by plastic stents at this time.

\subsection{Is imaging of the pancreatic duct necessary before transluminal stents are retrieved?}

\section{RECOMMENDATION}

ESGE suggests performing imaging (preferably secretinenhanced magnetic resonance cholangiopancreatography) of the main pancreatic duct prior to stent removal after endoscopic drainage of walled-off necrosis.

Weak recommendation, very low quality evidence.

An MPD rupture could lead to a recurrent collection after removal of the transluminal stents [184,204]. Some centers therefore perform imaging of the MPD by CE-CT, MRCP with secretin, and/or ERCP prior to drainage of and/or stent removal from WON. No studies have investigated if management based on standard imaging of the MPD prior to removal of transluminal stents decreases the number of recurrent PFCs [206].

CE-CT has been reported as adequately visualizing the MPD in $75 \%-100 \%$ of patients, but probably this is an overestimation because of the low quality of the studies [207, 208]. Imaging with MRCP provides a non-invasive and precise evaluation of the pancreatic parenchyma and MPD morphology. Secretin injection increases the sensitivity of the assessment of MPD integrity from $47.1 \%$ to $66.4 \%[45,209,210]$.

\subsection{What proportion of patients develop recurrence after treatment?}

Recurrence in the form of a necrotic cavity or pseudocyst has been reported in approximately $10 \%$ of patients after any type of endoscopic treatment; for WON, it was reported to be $9.4 \%$ after endoscopic transmural drainage (single or multiple transluminal gateway technique) in 53 patients [184], $7.8 \%$ after combined percutaneous and endoscopic drainage in 103 patients [191], and 10.9\% (7\% - 15\%) after endoscopic necrosectomy in a meta-analysis (8 studies, 233 patients) [197].

\subsection{How should disconnected pancreatic duct syndrome be managed?}

\section{RECOMMENDATION}

ESGE recommends long-term indwelling of transluminal plastic stents after transluminal drainage of walled-off necrosis in patients with proven disconnected pancreatic duct syndrome.

Strong recommendation, low quality evidence.

\section{RECOMMENDATION}

ESGE suggests against combining transluminal drainage with routine stenting of the pancreatic duct in patients with disconnected pancreatic duct syndrome. Where partial main pancreatic duct disruption has occurred, bridging of the disruption with a stent can be considered. Weak recommendation, low quality evidence.

If endoscopic drainage of WON has been performed in a patient with a disrupted MPD, long-term indwelling of transluminal plastic stents is indicated $[184,204]$. One retrospective study that included only a small number of patients with WON suggested that combining transpapillary and transluminal drainage would improve outcome [181].

If drainage of WON has not yet been performed or is not indicated, there is no indication for transpapillary stenting. Where partial MPD disruption has occurred, transpapillary stenting can be considered, preferably with the stent bridging the MPD disruption [211,212]. If transpapillary stenting of a partial disruption fails or where there is complete disruption, EUS-guided MPD drainage can be considered [213-215]. However, high quality data are scarce at the moment.

If endoscopy fails and a recurrent PFC occurs, surgery (distal pancreatectomy or Roux-en-Y drainage) can offer an alternative with success rates over $90 \%$, but diabetes ensues in the vast majority of patients [216-218] (Table e15, available online in Supplementary material).

A recent retrospective study showed that DPDS occurred more frequently in patients with WON compared with other PFCs $(68.3 \%$ vs. $31.7 \%)$ and was associated with a greater need for hybrid treatment (31.1\% vs. $4.8 \%$; $P<0.01)$, re-interventions ( $30 \%$ vs. $18.5 \% ; P=0.03)$, and rescue surgery $(13.2 \%$ vs. $4.8 \% ; P=0.02)$, and a longer length of stay [219]. 


\subsection{How should external pancreatic fistulas be managed?}

\section{RECOMMENDATION}

ESGE suggests that the initial management for external pancreatic fistulas should be conservative; intervention can be considered for patients who develop associated complications and in patients with persistent external pancreatic fistulas.

Weak recommendation, low quality evidence.

\section{RECOMMENDATION}

ESGE suggests considering endoscopic transluminal drainage (possibly in the setting of hybrid procedures) for an external pancreatic fistula associated with a partial or complete main pancreatic duct disruption and an adjacent pancreatic fluid collection.

Weak recommendation, low quality evidence.

An external pancreatic fistula is defined as the output of any measurable volume of fluid (via a percutaneous drain, a drainage canal after removal of a percutaneous drain, or from a surgical wound) with an increased fluid amylase concentration ( $\geq 3$ times the serum value) [220-222]. Initial management of pancreatic fistulas can be conservative unless sepsis is present because most will close spontaneously after a median interval of 70 days $[220,221]$.

Where an external pancreatic fistula is associated with partial MPD disruption and no PFC larger than $5 \mathrm{~cm}$ exists, transpapillary stenting can be considered. However, bridging the site of leakage with a pancreatic stent is successful in only $27 \%$ of patients $(9 \%-69 \%)$ [221-223]. In the only study comparing endoscopic transpapillary stenting and conservative management, the rate of external pancreatic fistula closure was not significantly different: $84 \%$ after stenting vs. $75 \%$ after conservative management $(P=0.18)$ [221]. The median times to closure were 71 days after stenting and 120 days with conservative management, which were not significantly different $(P=$ $0.13)$ [221].

One of the aims of dual-modality (percutaneous and endoscopic) drainage is to achieve a lower incidence of external pancreatic fistulas than occurs after PCD or surgical necrosectomy (incidence approximately $30 \%$, ranging from $7 \%$ to $79 \%$ ) [91, $187,220-226]$. In a retrospective review of 103 patients who completed dual-modality drainage, the rate of external pancreatic fistulas was $0 \%$ [191].

Endoscopic transluminal drainage can also be considered in patients with an established external pancreatic fistula associated with a partial or complete MPD disruption, with or without a PFC. With this procedure, an external pancreatic fistula can be transformed into an internal fistula, with consequent closure of the cutaneous orifice [227]. If a PFC is present, it can be drained under EUS guidance and, if this is not possible, a transient collection can be created by injecting saline into the external fistula; the collection is then punctured, so internalizing the tract of the pancreatic juice [227].

In patients with a persistent or recurrent external pancreatic fistula or where there has been failure of conservative and less invasive treatment, surgery (e.g. tail resection or ultimately a pancreaticojejunostomy) is still indicated as a last-resort treatment [220 - 222] (Table e16, available online in Supplementary materials).

\section{Disclaimer}

ESGE guidelines represent a consensus of best practice based on the available evidence at the time of preparation. They may not apply to all situations and should be interpreted in the setting of specific clinical situations and resource availability. They are intended to be an educational tool to provide information that may support endoscopists in providing care to patients. They are not rules and should not be utilized to establish a legal standard of care.

\section{Competing interests}

J. Albert has received speaker's honoraria from Fujifilm (2015 - 2016), Falk foundation, and Covidien/Medtronic (2015 - 2017), and both research and speaker's honoraria from Olympus Europe (2015-2017). A. Badaoui received a travel grant from Boston Scientific (2016). $M$. Barthet is a consultant for and receives research support from Boston Scientific (2016 to present). J. Devière has received research support from Cook Medical (until 2016) and from Boston Scientific (ongoing); his department is receiving research support from Olympus (ongoing). I. Hritz is a consultant (speaker/tutor) for Olympus Europe (ongoing). I. Papanikolaou is co-editor for social media with the Endoscopy journal. J.-W. Poley has received consultancy, travel, and speaker's fees from Cook Endoscopy and Boston Scientific (ongoing). S. Seewald has received consultancy fees from Boston Scientific (until 2016), and from Olympus and Cook Medical (ongoing). J. van Hooft received lecture fees from Medtronics $(2014-2015)$ and a consultancy fee from Boston Scientific (2014 - 2016); her department received research grants from Cook Medical and Abbott (2014-2017). K. van Lienden is receiving consultancy and speaker's fees from Cook Medical (ongoing). M. Arvanitakis, M. A. Bali, M. Besselink, M. Delhaye, J.-M. Dumonceau, A. Ferreira, T. Gyökeres, T. Hucl, M. Milashka, H. van Santvoort, G. Vanbiervliet, and R. Voermans have no competing interests.

\section{Acknowledgment}

The authors gratefully acknowledge Dr Mouen A. Khashab, Director of Therapeutic Endoscopy, Johns Hopkins Hospital, Baltimore, USA and Professor Marco Bruno, Dept. Gastroenterology \& Hepatology, Erasmus Medical Center, Rotterdam, the Netherlands for their valuable contribution and review of this guideline. 


\section{References}

[1] Working Group IAP/APA Acute Pancreatitis Guidelines. IAP/APA evidence-based guidelines for the management of acute pancreatitis. Pancreatology 2013; 13: e1 - e15

[2] Singh VK, Bollen TL, Wu BU et al. An assessment of the severity of interstitial pancreatitis. Clin Gastroenterol Hepatol 2011; 9: 1098 1103

[3] van Santvoort HC, Bakker O], Bollen TL et al. A conservative and minimally invasive approach to necrotizing pancreatitis improves outcome. Gastroenterology 2011; 141: $1254-1263$

[4] Harbour R, Miller J. A new system for grading recommendations in evidence based guidelines. BMJ 2001; 323: 334-336

[5] Dellinger EP, Forsmark CE, Layer P et al. Determinant-based classification of acute pancreatitis severity: an international multidisciplinary consultation. Ann Surg 2012; 256: 875-880

[6] Banks PA, Bollen TL, Dervenis C et al. Classification of acute pancreatitis-2012: revision of the Atlanta classification and definitions by international consensus. Gut 2013; 62: 102-111

[7] Nawaz H, Mounzer R, Yadav D et al. Revised Atlanta and determinantbased classification: application in a prospective cohort of acute pancreatitis patients. Am J Gastroenterol 2013; 108: 1911 - 1917

[8] Bansal SS, Hodson J, Sutcliffe RS et al. Performance of the revised Atlanta and determinant-based classification for severity in acute pancreatitis. Br J Surg 2016; 103: 427-433

[9] Chen Y, Ke L, Tong Z et al. Association between severity and the Determinant-Based Classification, Atlanta 2012 and Atlanta 1992, in acute pancreatitis. A clinical retrospective study. Medicine 2015; 94 : $1-7$

[10] Kadiyala V, Suleiman SL, McNabb-Baltar J et al. The Atlanta classification, revised Atlanta classification, and determinant-based classification of acute pancreatitis. Which is best at stratifying outcomes? Pancreas 2016; 45: 510-515

[11] Fernandes SR, Carvalho J, Santos P et al. Atlanta, revised Atlanta, and Determinant-based classification-application in a cohort of Portuguese patients with acute pancreatitis. Eur J Gastroenterol Hepatol 2016; $28: 20-24$

[12] Thandassery RB, Yadav TD, Dutta $U$ et al. Prospective validation of 4category classification of acute pancreatitis severity. Pancreas 2013; 42: $392-396$

[13] Acevedo-Piedra NG, Moya-Hoyo N, Rey-Riveiro M et al. Validation of the determinant-based classification and revision of the Atlanta classification systems for acute pancreatitis. Clin Gastroenterol Hepatol 2014; $12: 311-316$

[14] Choi J-H, Kim M-H, Oh D et al. Clinical relevance of the revised Atlanta classification focusing on severity stratification system. Pancreatology 2014; 14: $324-329$

[15] Talukdar R, Bhattacharrya A, Rao B et al. Clinical utility of the revised Atlanta classification of acute pancreatitis in a prospective cohort: Have all loose ends been tied? Pancreatology 2014; 14: 257 - 262

[16] Guo Q, Li M, Chen Y et al. Determinant-based classification and revision of the Atlanta classification, which one should we choose to categorize acute pancreatitis? Pancreatology 2015; 15: 331 - 336

[17] Andersson E, Ansari D, Andersson R. Major haemorrhagic complications of acute pancreatitis. Br J Surg 2010; 97: 1379-1384

[18] Wang M, Wei A, Guo Q et al. Clinical outcomes of combined necrotizing pancreatitis versus extrapancreatic necrosis alone. Pancreatology 2016; 16: 57-65

[19] Balthazar EJ, Robinson DL, Megibow AJ et al. Acute pancreatitis: value of CT in establishing prognosis. Radiology 1990; 174: 331 - 336
[20] Arvanitakis M, Delhaye M, De Maertelaere V et al. Computed tomography and magnetic resonance imaging in the assessment of acute pancreatitis. Gastroenterology 2004; 126: 715-723

[21] Thoeni RF. Imaging of acute pancreatitis. Radiol Clin North Am 2015; 53: $1189-1208$

[22] Bakker OJ, van Santvoort H, Besselink MG et al. Extrapancreatic necrosis without pancreatic parenchymal necrosis: a separate entity in necrotising pancreatitis? Gut 2013; 62: 1475 - 1480

[23] Garg PK, Sharma M, Madan K et al. Primary conservative treatment results in mortality comparable to surgery in patients with infected pancreatic necrosis. Clin Gastroenterol Hepatol 2010; 8: 1089-1094

[24] Mounzer R, Langmead C], Bechien U et al. Comparison of existing clinical scoring systems to predict persistent organ failure in patients with acute pancreatitis. Gastroenterology 2012; 142: 1476-1482

[25] Koutroumpakis E, Wu BU, Bakker O] et al. Admission hematocrit and rise in blood urea nitrogen at $24 \mathrm{~h}$ outperform other laboratory markers in predicting persistent organ failure and pancreatic necrosis in acute pancreatitis: a post hoc analysis of three large prospective databases. Am J Gastroenterol 2015; 110: 1707-1716

[26] Mofidi R, Duff MD, Wigmore SJ et al. Association between early systemic inflammatory response, severity of multiorgan dysfunction and death in acute pancreatitis. Br J Surg 2006; 93: 738 - 744

[27] Singh VK, Wu BU, Bollen TL et al. Early systemic inflammatory response syndrome is associated with severe acute pancreatitis. Clin Gastroenterol Hepatol 2009; 7: 1247 - 1251

[28] Yang C], Chen J, Phillips AR et al. Predictors of severe and critical acute pancreatitis: A systematic review. Dig Liver Dis 2014; 46: 446-451

[29] Singh VK, Wu BU, Bollen TL et al. A prospective evaluation of the bedside index for severity in acute pancreatitis score in assessing mortality and intermediate markers of severity in acute pancreatitis. Am J Gastroenterol 2009; 104: 966 - 971

[30] Khanna AK, Meher S, Prakash S et al. Comparison of Ranson, Glasgow, MOSS, SIRS, BISAP, APACHE-II, CTSI Scores, IL-6, CRP, and procalcitonin in predicting severity, organ failure, pancreatic necrosis and mortality in acute pancreatitis. HPB Surg 2013; 2013: 367581

[31] Papachristou GI, Muddana V, Yadav D et al. Comparison of BISAP, Ranson's, APACHE-II and CTSI scores in predicting organ failure, complications, and mortality in acute pancreatitis. Am J Gastroenterol 2010; 105: $435-441$

[32] Park JY, Jeon TJ, Ha TH et al. Bedside index for severity in acute pancreatitis: comparison with other scoring systems in predicting severity and organ failure. Hepatobil Pancreat Dis Int 2013; 12: 645-650

[33] Tenner S, Baillie J, DeWitt J et al. American College of Gastroenterology guidelines: management of acute pancreatitis. Am J Gastroenterol 2013; 108: 1400-1415

[34] Bollen TL, Singh VK, Maurer R et al. A comparative evaluation of radiologic and clinical scoring systems in the early prediction of severity in acute pancreatitis. Am J Gastroenterol 2012; 107: 612 -619

[35] Thoeni RF. The revised Atlanta classification of acute pancreatitis: its importance for the radiologist and its effect on treatment. Radiology 2012; $262: 751-764$

[36] Bollen TL. Acute pancreatitis: international classification and nomenclature. Clin Radiol 2016; 71: 121-133

[37] Mortele KJ, Wiesner W, Intriere L et al. A modified CT severity index for evaluating acute pancreatitis: improved correlation with patient outcome. AJR Am J Roentgenol 2004; 183: 1261 - 1265

[38] Bollen TL, Singh VK, Maurer R et al. Comparative evaluation of the modified CT severity index and CT severity index in assessing severity of acute pancreatitis. AJR Am J Roentgenol 2011; 197: 386-392

[39] Lecesne R, Taourel P, Bret PM et al. Acute pancreatitis: interobserver agreement and correlation of $\mathrm{CT}$ and MR cholangiopancreatography with outcome. Radiology 1999; 211: 727-735 
[40] Stimac D, Miletic D, Radic M et al. The role of nonenhanced magnetic resonance imaging in the early assessment of acute pancreatitis. Am J Gastroenterol 2007; 102: 997-1004

[41] Viremouneix L, Monneuse O, Gautier $G$ et al. Prospective evaluation of nonenhanced MR imaging in acute pancreatitis. J Magn Reson Imaging 2007; 26: $331-338$

[42] Rickes S, Uhle C, Kahl S et al. Echo enhanced ultrasound: a new valid initial imaging approach for severe acute pancreatitis. Gut 2006; 55 : $74-78$

[43] Ripolles T, Martinez MJ, Lopez E et al. Contrast-enhanced ultrasound in the staging of acute pancreatitis. Eur Radiol 2010; 20: 2518-2523

[44] Lu Q, Zhong Y, Wen XR et al. Can contrast-enhanced ultrasound evaluate the severity of acute pancreatitis? Dig Dis Sci 2011; 56: 1578 1584

[45] Gillams AR, Kurzawinski T, Lees WR. Diagnosis of duct disruption and assessment of pancreatic leak with dynamic secretin-stimulated MR cholangiopancreatography. AJR Am J Roentgenol 2006; 186: 499 506

[46] Morgan DE, Baron TH, Smith JK et al. Pancreatic fluid collections prior to intervention: evaluation with MR imaging compared with $\mathrm{CT}$ and US. Radiology 1997; 203: 773-778

[47] Kamal A, Singh VK, Akshintala VS et al. CT and MRI assessment of symptomatic organized pancreatic fluid collections and pancreatic duct disruption: an interreader variability study using the revised Atlanta classification 2012. Abdom Imaging 2015; 40: 1608-1616

[48] Rana SS, Bhasin DK, Sharma RK et al. Do the morphological features of walled off pancreatic necrosis on endoscopic ultrasound determine the outcome of endoscopic transmural drainage? Endosc Ultrasound 2014; 3: $118-122$

[49] Rana SS, Chaudhary V, Sharma R et al. Comparison of abdominal ultrasound, endoscopic ultrasound and magnetic resonance imaging in detection of necrotic debris in walled-off pancreatic necrosis. Gastroenterol Rep 2016; 4: 50 - 53

[50] van Baal MC, Bollen TC, Bakker O] et al. The role of routine fine-needle aspiration in the diagnosis of infected necrotizing pancreatitis. Surgery 2014; 155 : $442-448$

[51] Mofidi R, Suttie S, Patil PV et al. The value of procalcitonin at predicting the severity of acute pancreatitis and development of infected pancreatic necrosis: systematic review. Surgery 2009; 146: $72-81$

[52] Islim F, Salik AE, Bayramoglu S et al. Non-invasive detection of infection in acute pancreatic and acute necrotic collections with diffusionweighted magnetic resonance imaging: preliminary findings. Abdom Imaging 2014; 39: 472-481

[53] Borens B, Arvanitakis M, Absil J et al. Added value of diffusionweighted magnetic resonance imaging for the detection of pancreatic fluid collection infection. Eur Radiol 2017; 27: 1064 - 1073

[54] Rodriguez JR, Razo AO, Targarona J et al. Debridement and closed packing for sterile or infected necrotizing pancreatitis: insights into indications and outcomes in 167 patients. Ann Surg 2008; 247: 294 299

[55] Wu BU, Hwang JQ, Gardner TH et al. Lactated Ringer's solution reduces systemic inflammation compared with saline in patients with acute pancreatitis. Clin Gastroenterol Hepatol 2011; 9: 710 - 717

[56] Sharma V, Rana SS, Sharma R et al. Naso-jejunal fluid resuscitation in predicted severe acute pancreatitis: Randomized comparative study with intravenous Ringer's lactate. J Gastroenterol Hepatol 2016; 31: $265-269$

[57] Gardner TB, Vege SS, Chari ST et al. Faster rate of initial fluid resuscitation in severe acute pancreatitis diminishes in-hospital mortality. Pancreatology 2009; 9: 770 - 776

[58] Wall I, Badalov N, Baradarian R et al. Decreased Mortality in Acute Pancreatitis Related to Early Aggressive Hydration. Pancreas 2011; 40: $547-550$
[59] Zeng YB, Zhan XB, Guo XR et al. Risk factors for pancreatic infection in patients with severe acute pancreatitis: An analysis of 163 cases. J Dig Dis 2014; 15: $377-385$

[60] Mole D], Hall A, McKeown D et al. Detailed fluid resuscitation profiles in patients with severe acute pancreatitis. HPB (Oxford) 2011; 13: $51-58$

[61] Buxbaum J, Yan A, Yeh K et al. Aggressive hydration with lactated Ringer's solution reduces pancreatitis after endoscopic retrograde cholangiopancreatography. Clin Gastroenterol Hepatol 2014; 12: $303-307$

[62] Choi JH, Kim H], Lee BU et al. Vigorous periprocedural hydration with lactated Ringer solution reduces the risk of pancreatitis after retrograde cholangiopancreatography in hospitalized patients. Clin Gastroenterol Hepatol 2017; 15: 86-89

[63] Shaygan-Nejad A, Masjedizadeh AR, Ghavidel A et al. Aggressive hydration with Lactated Ringer's solution as the prophylactic intervention for post-endoscopic retrograde cholangiopancreatography pancreatitis: A randomized controlled double-blind clinical trial. J Res Med Sci 2015; 20: 838-843

[64] Mao EQ, Tang YQ, Li L et al. Strategy of controlling fluid resuscitation for severe acute pancreatitis in acute phase. Chin J Surg 2007; 45: $1331-1334$

[65] Mao EQ, Tang YQ, Fei J et al. Fluid therapy for severe acute pancreatitis in acute response stage. Chin Med J 2009; 122: 169-173

[66] Mao EQ, Fei J, Peng YB et al. Rapid hemodilution is associated with increased sepsis and mortality among patients with severe acute pancreatitis. Chin Med J 2010; 123: 1639-1644

[67] Weitz G, Woitalla J, Wellhöner P et al. Detrimental effect of high volume fluid administration in acute pancreatitis-a retrospective analysis of 391 patients. Pancreatology 2014; 14: 478-483

[68] Eckerwall G, Olin H, Andersson B et al. Fluid resuscitation and nutritional support during severe acute pancreatitis in the past: What have we learned and how can we do better? Clin Nutr 2006; 25: 497 - 504

[69] Kuwabara K, Matsuda S, Fushimi K et al. Early crystalloid fluid volume management in acute pancreatitis: Association with mortality and organ failure. Pancreatology 2011; 11: 351-361

[70] De Madaria E, Soler-Sala G, Sánchez-Payá J et al. Influence of fluid therapy on the prognosis of acute pancreatitis: a prospective cohort study. Influence of fluid therapy on the prognosis of acute pancreatitis: a prospective cohort study. Am J Gastroenterol 2011; 106: 1843 1850

[71] Wu BU, Bakker OJ, Papachristou Gl et al. Blood Urea Nitrogen in the early assessment of acute pancreatitis. Arch Intern Med 2011; 171: $669-676$

[72] Baillargeon JD, Orav J, Ramagopal V et al. Hemoconcentration as an early risk factor for necrotizing pancreatitis. Am J Gastroenterol 1998; 93: $2130-2134$

[73] Yang C, Yang Z, Chen X et al. Inverted U-Shaped relationship between central venous pressure and intra-abdominal pressure in the early phase of severe acute pancreatitis: A retrospective study. PLoS One 2015; 10: e0128493

[74] Sun Y, Lu ZH, Zhang XS et al. The effects of fluid resuscitation according to PiCCO on the early stage of severe acute pancreatitis. Pancreatology 2015; 15: $497-502$

[75] Huber W, Umgelter A, ReindI W et al. Volume assessment in patients with necrotizing pancreatitis: A comparison of intrathoracic blood volume index, central venous pressure, and hematocrit, and their correlation to cardiac index and extravascular lung water index. Crit Care Med 2008; 36: $2348-2354$

[76] Wittau M, Mayer B, Scheele J et al. Systematic review and meta-analysis of antibiotic prophylaxis in severe acute pancreatitis. Scand J Gastroenterol 2011; 46: 261 - 270 
[77] Villatoro E, Mulla M, Larvin M. Antibiotic therapy for prophylaxis against infection of pancreatic necrosis in acute pancreatitis. Cochrane Database Syst Rev 2010; 5: CD002941

[78] Yao L, Huang X, Li Y et al. Prophylactic antibiotics reduce pancreatic necrosis in acute necrotizing pancreatitis: a meta-analysis of randomized trials. Dig Surg 2010; 27: $442-449$

[79] Jafri NS, Mahid SS, Idstein SR et al. Antibiotic prophylaxis is not protective in severe acute pancreatitis: a systematic review and meta-analysis. Am J Surg 2009; 197: $806-813$

[80] Bai Y, Gao J, Zou DW et al. Prophylactic antibiotics cannot reduce infected pancreatic necrosis and mortality in acute necrotizing pancreatitis: evidence from a meta-analysis of randomized controlled trials. Am J Gastroenterol 2008; 103: 104-110

[81] Hart PA, Bechtold ML, Marshall JB et al. Prophylactic antibiotics in necrotizing pancreatitis: a meta-analysis. South Med J 2008; 101: $1126-1131$

[82] Xu T, Cai Q. Prophylactic antibiotic treatment in acute necrotizing pancreatitis: results from a meta-analysis. Scand J Gastroenterol 2008; 43: $1249-1258$

[83] Lim CL, Lee W, Liew YX et al. Role of antibiotic prophylaxis in necrotizing pancreatitis: a meta-analysis. J Gastrointest Surg 2015; 19 : $480-491$

[84] Trikudanathan G, Navaneethan U, Vege SS. Intra-abdominal fungal infections complicating acute pancreatitis: a review. Am J Gastroenterol 2011; 106: $1188-1192$

[85] Schwender B], Gordon SR, Gardner TB. Risk factors for the development of intra-abdominal fungal infections in acute pancreatitis. Pancreas 2015; 44: 805-807

[86] Sun S, Yang K, He X et al. Probiotics in patients with severe acute pancreatitis: a meta-analysis. Arch Surg 2009; 394: 171-177

[87] Fritz S, Hackert T, Hartwig W et al. Bacterial translocation and infected pancreatic necrosis in acute necrotizing pancreatitis derives from small bowel rather than for colon. Am J Surg 2010; 200: 111-117

[88] Beger HG, Bittner R, Block S et al. Bacterial contamination of pancreatic necrosis: a perspective clinical study. Gastroenterology 1986; 91: $433-438$

[89] Bassi C, Pederzoli P, Vesentini S et al. Behavior of antibiotics during human necrotizing pancreatitis. Antimicrob Agents Chemother 1994; 38: $830-836$

[90] Da Costa DW, Boerma D, van Santvoort HC et al. Staged multidisciplinary step-up management for necrotizing pancreatitis. Br J Surg 2014; 101: 65-79

[91] Bakker OJ, van Santvoort HC, van Brunschot S et al. Endoscopic transgastric vs surgical necrosectomy for infected necrotizing pancreatitis. A randomized trial. JAMA 2012; 307: 1053-1061

[92] De Waele J]. Rational use of antimicrobials in patients with severe acute pancreatitis. Semin Respir Crit Care Med 2011; 32: 174-180

[93] Wu LM, Sankaran SJ, Plank LD et al. Meta-analysis of gut barrier dysfunction in patients with acute pancreatitis. Br J Surg 2014; 101: $1644-1656$

[94] Capurso G, Zerboni G, Signoretti M et al. Role of the gut barrier in acute pancreatitis. J Clin Gastroenterol 2012; 46: S46-S51

[95] Lodewijkx PJ, Besselink MG, Witteman B] et al.; Dutch Pancreatitis Study Group. Nutrition in acute pancreatitis: a critical review. Expert Rev Gastroenterol Hepatol 2016; 10: 571 - 580

[96] Yi F, Ge L, Zhao J et al. Meta-analysis: total parenteral nutrition versus total enteral nutrition in predicted severe acute pancreatitis. Intern Med 2012; 51: $523-530$

[97] Al-Omran M, Albalawi ZH, Tashkandi MF et al. Enteral versus parenteral nutrition for acute pancreatitis. Cochrane Database Syst Rev 2010; 20: CD002837
[98] Petrov MS, van Santvoort HC, Besselink MG et al. Enteral nutrition and the risk of mortality and infectious complications in patients with severe acute pancreatitis: a meta-analysis of randomized trials. Arch Surg 2008; 143: $1111-1117$

[99] Li JY, Yu T, Chen GC et al. Enteral nutrition within 48 days of admission improves clinical outcomes of acute pancreatitis by reducing complications: a meta-analysis. PLoS One 2013; 8: e64926

[100] Petrov MS, Pylypchuk RD, Uchugina AF. A systematic review on the timing of artificial nutrition in acute pancreatitis. Br J Nutr 2009; 101: $787-793$

[101] Wereszcynska-Siemiatkowska U, Swidnicka-Siergiejko A, Siemiatkowski $A$ et al. Early enteral nutrition is superior to delayed enteral nutrition for the prevention of infected necrosis and mortality in acute pancreatitis. Pancreas 2013; 42: 640 - 646

[102] Sun JK, Mu XW, Li WQ et al. Effects of early enteral nutrition on immune function of severe acute pancreatitis patients. World J Gastroenterol 2013; 19: $917-922$

[103] Bakker OJ, van Brunschot S, van Santvoort HC et al. Dutch Pancreatitis Study Group. Early versus on-demand nasoenteric tube feeding in acute pancreatitis. NEJM 2014; 371: 1983-1993

[104] Arabi YM, Aldawood As, Solaiman O. Permissive underfeeding or standard enteral feeding in critical illness. NEJM 2015; 373: 1175 1176

[105] Stimac D, Poropat G, Hauser G et al. Early nasojejunal tube feeding versus nil-by-mouth in acute pancreatitis: a randomized clinical trial. Pancreatology 2016; 16: 523-528

[106] Poropat G, Giljaca V, Hauser G et al. Enteral nutrition formulations for acute pancreatitis. Cochrane Database Syst Rev 2015: CD010605

[107] Petrov MS, Loveday BP, Pylypchuk RD et al. Systematic review and meta-analysis of enteral nutrition formulations in acute pancreatitis. Br J Surg 2009; 96: $1243-1252$

[108] Eatock FC, Chong P, Menezes N et al. A randomized study of early nasogastric versus nasojejunal feeding in severe acute pancreatitis. Am J Gastroenterol 2005; 100: 432-439

[109] Kumar A, Singh N, Prakash S et al. Early enteral nutrition in severe acute pancreatitis: a prospective randomized controlled trial comparing nasojejunal and nasogastric routes. J Clin Gastroenterol 2006 40: $431-434$

[110] Singh N, Sharma B, Sharma M et al. Evaluation of early enteral feeding through nasogastric and nasojejunal tube in severe acute pancreatitis: a noninferiority randomized controlled trial. Pancreas 2012; 41: $153-159$

[111] Piciucchi M, Merola E, Marignani M et al. Nasogastric or nasointestinal feeding in severe acute pancreatitis. World J Gastroenterol 2010; 16: $3692-3696$

[112] Eckerwall G, Axelsson JB, Andersson RG. Early nasogastric feeding in predicted severe acute pancreatitis: a clinical, randomized study. Ann Surg 2006; 244: 959-965

[113] Nally DM, Kelly EG, Clarke M et al. Nasogastric nutrition is efficacious in severe acute pancreatitis: a systematic review and meta-analysis. Br J Nutr 2014; 112: 1769 - 1778

[114] Petrov MS, Correia MI, Windsor JA. Nasogastric tube feeding in predicted severe acute pancreatitis. A systematic review of the literature to determine safety and tolerance. JOP 2008; 9: 440-448

[115] Chang YS, Fu HQ, Xiao YM et al. Nasogastric or nasojejunal feeding in predicted severe acute pancreatitis: a meta-analysis. Crit Care 2013; 17: R118

[116] Zhu Y, Yin H, Zhang R et al. Nasogastric nutrition versus nasojejunal nutrition in patients with severe acute pancreatitis: a meta-analysis of randomized controlled trials. Gastroenterol Res Pract 2016; 2016 : 6430632

[117] Neoptolemos JP, Carr-Locke DL, London NJ et al. Controlled trial of urgent endoscopic retrograde cholangiopancreatography and 
endoscopic sphincterotomy versus conservative treatment for acute pancreatitis due to gallstones. Lancet 1988; 2: 979-983

[118] Fan ST, Lai EC, Mok FP et al. Early treatment of acute biliary pancreatitis by endoscopic papillotomy. NEJM 1993; 328: 228-232

[119] Folsch UR, Nitsche R, Ludtke R et al. Early ERCP and papillotomy compared with conservative treatment for acute biliary pancreatitis. The German Study Group on Acute Biliary Pancreatitis. NEJM 1997; 336: $237-242$

[120] Oria A, Cimmino D, Ocampo C et al. Early endoscopic intervention versus early conservative management in patients with acute gallstone pancreatitis and biliopancreatic obstruction: a randomized clinical trial. Ann Surg 2007; 245: 10-17

[121] Chen P, Hu B, Wang C et al. Pilot study of urgent endoscopic intervention without fluoroscopy on patients with severe acute biliary pancreatitis in the intensive care unit. Pancreas 2010; 39: 398-402

[122] Tang Y, Xu Y, Liao G. Effect of early endoscopic treatment for patients with severe acute biliary pancreatitis. Chin J Gen Surg 2010; 19: $801-804$

[123] Tse F, Yuan Y. Early routine endoscopic retrograde cholangiopancreatography strategy versus early conservative management strategy in acute gallstone pancreatitis. Cochrane Database Syst Rev 2012; 5: CD009779

[124] Khreiss M, Zenati M, Clifford A et al. Cyst gastrostomy and necrosectomy for the management of sterile walled-off pancreatic necrosis: a comparison of minimally invasive surgical and endoscopic outcomes at a high-volume pancreatic center. Gastrointest Surg 2015; 19: $1441-1448$

[125] Munene G, Dixon E, Sutherland F et al. Open transgastric debridement and internal drainage of symptomatic non-infected walled-off pancreatic necrosis. HPB (Oxford) 2011; 13: 234-239

[126] Trikudanathan G, Vege SS. Current concepts of the role of abdominal compartment syndrome in acute pancreatitis-an opportunity or merely an epiphenomenon. Pancreatology 2014; 14: 238-243

[127] Van Brunschot S, Schut AJ, Bouwense SA et al. Abdominal compartment syndrome in acute pancreatitis: a systematic review. Pancreas 2014; 43: $665-674$

[128] Baril NB, Ralls PW, Wren SM et al. Does an infected peripancreatic fluid collection or abscess mandate operation? Ann Surg 2000; 231: $361-367$

[129] Ramesh H, Prakash K, Lekha V et al. Are some cases of infected pancreatic necrosis treated without intervention? Dig Surg 2003; 20: $296-300$

[130] Runzi M, Niebel W, Goebell H et al. Severe acute pancreatitis: Nonsurgical treatment of infected necroses. Pancreas 2005; 30: 195 199

[131] Mouli VP, Sreenivas V, Garg PK et al. Efficacy of conservative treatment, without necrosectomy, for infected pancreatic necrosis: A systematic review and meta-analysis. Gastroenterology 2013; 144: $333-340$

[132] van Baal MC, van Santvoort HC, Bollen TL et al. Systematic review of percutaneous catheter drainage as primary treatment for necrotizing pancreatitis. $\mathrm{Br}$ J Surg 2011; 98: $18-27$

[133] van Santvoort HC, Besselink MG, Bakker OJ et al. A step-up approach or open necrosectomy for necrotizing pancreatitis. NEJM 2010; 362: $1491-1502$

[134] Bang JY, Holt BA, Hawes RH et al. Outcomes after implementing a tailored endoscopic step-up approach to walled-off necrosis in acute pancreatitis. Br J Surg 2014; 101: 1729-1738

[135] Varadarajulu S, Phadnis MA, Christein JD et al. Multiple transluminal gateway technique for EUS-guided drainage of symptomatic walledoff pancreatic necrosis. Gastrointest Endosc 2011; 74: 74-80

[136] Seewald S, Groth S, Omar S et al. Aggressive endoscopic therapy for pancreatic necrosis and pancreatic abscess: a new safe and effective treatment algorithm (videos). Gastrointest Endosc 2005; 62: 92 100

[137] Seifert H, Wehrmann T, Schmitt T et al. Retroperitoneal endoscopic debridement for infected peripancreatic necrosis. Lancet 2000; 356: $653-655$

[138] Ross A, Gluck M, Irani S et al. Combined endoscopic and percutaneous drainage of organized pancreatic necrosis. Gastrointest Endosc 2010; 71: 79-84

[139] Varadarjaulu S, Wilcox CM, Tamhane A et al. Role of EUS in drainage of peripancreatic fluid collection not amenable for endoscopic transmural drainage. Gastrointest Endosc 2007; 66: 1107-1119

[140] Kahaleh M, Shami VM, Conaway MR et al. Endoscopic ultrasound drainage of pancreatic pseudocyst: a prospective comparison with conventional endoscopic drainage. Endoscopy 2006; 38: 355-359

[141] Varadarajulu S, Christein JD, Tamhane A et al. Prospective randomized trial comparing EUS and EGD for transmural drainage of pancreatic pseudocysts (with videos). Gastrointest Endosc 2008; 68: $1102-1111$

[142] Park DH, Lee SS, Moon SH et al. Endoscopic ultrasound-guided versus conventional transmural drainage for pancreatic pseudocysts: a prospective randomized trial. Endoscopy 2009; 41: 842 - 848

[143] Iwashita T, Nakai Y, Lee JG et al. Newly-developed, forward-viewing echoendoscope: A comparative pilot study to the standard echoendoscope in the imaging of abdominal organs and feasibility of endoscopic ultrasound-guided interventions. J Gastroenterol Hepatol 2012; 27: $362-367$

[144] Voermans RP, Eisendrath P, Bruno MJ et al. Initial evaluation of a novel prototype forward-viewing US endoscope in transmural drainage of pancreatic pseudocysts (with videos). Gastrointest Endosc 2007; 66: $1013-1017$

[145] Voermans RP, Ponchon T, Schumacher B et al. Forward-viewing versus oblique-viewing echoendoscopes in transluminal drainage of pancreatic fluid collections: A multicenter, randomized, controlled trial. Gastrointest Endosc 2011; 74: 1285-1293

[146] Varadarajulu S, Tamhane A, Blakely J. Graded dilation technique for EUS-guided drainage of peripancreatic fluid collections: an assessment of outcomes and complications and technical proficiency (with video). Gastrointest Endosc 2008; 68: 656-666

[147] Cremer M, Devière J, Baize M et al. New device for endoscopic cystoenterostomy. Endoscopy 1990; 22: 76-77

[148] Mukai S, Itoi T, Moriyasu F. Interventional endoscopy for the treatment of pancreatic pseudocyst and walled-off necrosis (with videos). J Hepatobiliary Pancreat Sci 2014; 21: E75 -E85

[149] Yasuda I, Nakashima M, Iwai T et al. Japanese multicenter experience of endoscopic necrosectomy for infected walled-off pancreatic necrosis: The JENIPaN study. Endoscopy 2013; 45: 627-634

[150] Thompson CC, Kumar N, Slattery J et al. A standardized method for endoscopic necrosectomy improves complication and mortality rates. Pancreatology 2016; 16: $66-72$

[151] Gardner TB, Coelho-Prabhu N, Gordon SR et al. Direct endoscopic necrosectomy for the treatment of walled-off pancreatic necrosis: results from a multicenter U.S. series. Gastrointest Endosc 2011; 73: $718-726$

[152] Kumar N, Conwell DL, Thompson CC. Direct endoscopic necrosectomy versus step-up approach for walled-off pancreatic necrosis: comparison of clinical outcome and health care utilization. Pancreas 2014; 43: 1334-1339

[153] van Brunschot S, Fockens P, Bakker OJ et al. Endoscopic transluminal necrosectomy in necrotizing pancreatitis: a systematic review. Surg Endosc 2014; 28: $1425-1438$

[154] Bang JY, Hawes R, Bartolucci A et al. Efficacy of metal and plastic stents for transmural drainage of pancreatic fluid collections: a systematic review. Dig Endosc 2015; 27: 486-498 
[155] Mukai S, Itoi T, Baron TH et al. EUS-guided placement of plastic vs biflanged metal stent for therapy of walled-off necrosis: a retrospective single center study. Endoscopy 2015; 47: 47 - 55

[156] Bapaye A, Dubale NA, Sheth KA et al. Endoscopic ultrasonographyguided transmural drainage of walled-off pancreatic necrosis: Comparison between a specially designed fully covered bi-flanged metal stent and multiple plastic stents. Dig Endosc 2017; 29: 104-110

[157] Bang JY, Hasan M, Navaneethan U et al. Lumen-apposing metal stents (LAMS) for pancreatic fluid collection (PFC) drainage: may not be business as usual. Gut 2017; 66: 2054-2056

[158] Mathers B, Moyer M, Mathew A et al. Percutaneous debridement and washout of walled-off abdominal abscess and necrosis using flexible endoscopy: a large single-center experience. Endosc Int Open 2016; 4: E102-E106

[159] Gornals JB, Consiglieri CF, Busquets J et al. Endoscopic necrosectomy of walled-off pancreatic necrosis using a lumen-apposing metal stent and irrigation technique. Surg Endosc 2016; 30: 2592 - 2602

[160] Schmidt PN, Novovic S, Roug $S$ et al. Endoscopic, transmural drainage and necrosectomy for walled-off pancreatic and peripancreatic necrosis is associated with low mortality-a single-center experience. Scand J Gastroenterol 2015; 50: 611-618

[161] Abdelhafez M, Elnegouly M, Hasab AllahMS et al. Transluminal retroperitoneal endoscopic necrosectomy with the use of hydrogen peroxide and without external irrigation: a novel approach for the treatment of walled-off pancreatic necrosis. Surg Endosc 2013; 27: $3911-3920$

[162] Rische S, Riecken B, Degenkolb J et al. Transmural endoscopic necrosectomy of infected pancreatic necroses and drainage of infected pseudocysts: a tailored approach. Scand J Gastroenterol 2013; 48: $231-240$

[163] Seewald S, Ang TL, Richter $\mathrm{H}$ et al. Long-term results after endoscopic drainage and necrosectomy of symptomatic pancreatic fluid collections. Dig Endosc 2012; 24: 36-41

[164] Jürgensen C, Neser F, Boese-Landgraf J et al. Endoscopic ultrasoundguided endoscopic necrosectomy of the pancreas: is irrigation necessary? Surg Endosc 2012; 26: 1359-1363

[165] Mukai S, Itoi T, Sofuni A et al. Expanding endoscopic interventions for pancreatic pseudocyst and walled-off necrosis. J Gastroenterol 2015; 50: $211-220$

[166] Seifert H, Biermer M, Schmitt W et al. Transluminal endoscopic necrosectomy after acute pancreatitis: a multicentre study with longterm follow-up (the GEPARD Study). Gut 2009; 58: 1260-1266

[167] Siddiqui AA, Adler DG, Nieto J et al. EUS-guided drainage of peripancreatic fluid collections and necrosis by using a novel lumen-apposing stent: a large retrospective, multicenter U.S. experience (with videos). Gastrointest Endosc 2016; 83: 699-707

[168] Charnley RM, Lochan R, Gray H et al. Endoscopic necrosectomy as primary therapy in the management of infected pancreatic necrosis. Endoscopy 2006; 38: 925-928

[169] Escourrou J, Shehab H, Buscail L et al. Peroral transgastric/transduodenal necrosectomy: success in the treatment of infected pancreatic necrosis. Ann Surg 2008; 248: $1074-1080$

[170] Aso A, Igarashi H, Matsui $\mathrm{N}$ et al. Large area of walled-off pancreatic necrosis successfully treated by endoscopic necrosectomy using a grasping-type scissors forceps. Dig Endosc 2014; 26: 474-477

[171] Voermans RP, Veldkamp MC, Rauws EA et al. Endoscopic transmural debridement of symptomatic organized pancreatic necrosis (with videos). Gastrointest Endosc 2007; 66: 909-916

[172] Gutierrez JP, Wilcox CM, Mönkemüller K. New technique to carry out endoscopic necrosectomy lavage using a pump. Dig Endosc 2014; 26: $117-118$

[173] Raczynski S, Teich N, Borte G et al. Percutaneous transgastric irrigation drainage in combination with endoscopic necrosectomy in ne- crotizing pancreatitis (with videos). Gastrointest Endosc 2006; 64: $420-424$

[174] Hritz I, Fejes R, Székely A et al. Endoscopic transluminal pancreatic necrosectomy using a self-expanding metal stent and high-flow water-jet system. World J Gastroenterol 2013; 19: 3685-3692

[175] Smith IB, Gutierrez JP, Ramesh J et al. Endoscopic extra-cavitary drainage of necrosis with fully covered self-expanding metal stents (fcSEMS) and staged lavage with a high-flow water jet system. Endosc Int Open 2015; 3: E154-E160

[176] Galasso D, Baron TH, Attili F et al. Endoscopic ultrasound-guided drainage and necrosectomy of walled-off pancreatic necrosis using a metal stent with an electrocautery-enhanced delivery system and hydrogen peroxide. Dig Dis Sci 2014; 59: 687-690

[177] Siddiqui AA, Easler J, Strongin A et al. Hydrogen peroxide-assisted endoscopic necrosectomy for walled-off pancreatic necrosis: a dual center pilot experience. Dig Dis Sci 2014; 59: 687-690

[178] Wedemeyer ], Kubicka S, Lankisch TO et al. Transgastrically placed endoscopic vacuum-assisted closure system as an addition to transgastric necrosectomy in necrotizing pancreatitis (with video). Gastrointest Endosc 2012; 76: 1238 - 1241

[179] Wallstabe I, Tiedemann A, Schiefke I. Endoscopic vacuum-assisted therapy of an infected pancreatic pseudocyst. Endoscopy 2011; 43 Suppl 2: E312-E313

[180] Wallstabe I, Tiedemann A, Schiefke I. Endoscopic vacuum-assisted therapy of infected pancreatic pseudocyst using a coated sponge. Endoscopy 2012; 44 Suppl 2: E49-E50

[181] Trevino JM, Tevino JM, Tamhane A et al. Successful stenting in ducta disruption favorably impacts treatment outcomes in patients undergoing transmural drainage of peripancreatic fluid collections. J Gastroenterol Hepatol 2010; 25: 526-531

[182] Varadarajulu S, Bang JY, Phadnis MA et al. Endoscopic Transmural Drainage of Peripancreatic Fluid Collections: Outcomes and Predictors of Treatment Success in 211 Consecutive Patients. J Gastrointest Surg 2011; 15: 2080-2088

[183] Yang D, Amin S, Gonzalez S et al. Transpapillary drainage has no added benefit on treatment outcomes in patients undergoing EUSguided transmural drainage of pancreatic pseudocysts: a large multicenter study. Gastrointest Endosc 2016; 83: 720 - 729

[184] Bang JY, Wilcox CM, Trevino J et al. Factors impacting treatment outcomes in the endoscopic management of walled-off pancreatic necrosis. J Gastroenterol Hepatol 2013; 28: 1725-1732

[185] Ang TL, Kwek ABE, Tan SS et al. Direct endoscopic necrosectomy: a minimally invasive endoscopic technique for the treatment of infected walled-off pancreatic necrosis and infected pseudocysts with solid debris. Singapore Med J 2013; 54: 206 -211

[186] Gluck M, Ross A, Irani S et al. Dual modality drainage for symptomatic walled-off pancreatic necrosis reduces length of hospitalization, radiological procedures, and number of endoscopies compared to standard percutaneous drainage. J Gastrointest Surg 2012; 16: $248-257$

[187] van Brunschot S. Endoscopic or surgical step-up approach for necrotizing pancreatitis, a multi-center randomized controlled trial. United European Gastroenterol J 2016; 4: A2

[188] Carter CR, McKay C], Imrie CW. Percutaneous necrosectomy and sinus tract endoscopy in the management of infected pancreatic necrosis: an initial experience. Ann Surg 2000; 232: 175-180

[189] Horvath KD, Kao LS, Wherry KL et al. A technique for laparoscopicassisted percutaneous drainage of infected pancreatic necrosis and pancreatic abscess. Surg Endosc 2001; 15: 1221 - 1225

[190] Shenvi S, Gupta R, Kang M et al. Timing of surgical intervention in patients of infected necrotizing pancreatitis not responding to percutaneous catheter drainage. Pancreatology 2016; 16: 778-787 
[191] Ross AS, Irani S, Gan SI et al. Dual-modality drainage of infected and symptomatic walled-off pancreatic necrosis: long-term clinical outcomes. Gastrointest Endosc 2014; 79: 929-935

[192] Papachristou GI, Takahashi N, Chahal P et al. Peroral endoscopic drainage/debridement of walled-off pancreatic necrosis. Ann Surg 2007; 245: 943 - 951

[193] Sarathi Patra P, Das K, Bhattacharyya A et al. Natural resolution or intervention for fluid collections in acute severe pancreatitis. $\mathrm{Br}$ ] Surg 2014; 101: $1721-1728$

[194] Hollemans RA, Bollen TL, van Brunschot S et al. Dutch Pancreatitis Study Group. Predicting success of catheter drainage in infected necrotizing pancreatitis. Ann Surg 2016; 263: 787 -792

[195] Babu RY, Gupta R, Kang M et al. Predictors of surgery in patients with severe acute pancreatitis managed by the step-up approach. Ann Surg 2013; 257: 737 - 750

[196] Cirocchi R, Trastulli S, Desiderio J et al. Minimally invasive necrosectomy versus conventional surgery in the treatment of infected pancreatic necrosis: a systematic review and a meta-analysis of comparative studies. Surg Laparosc Endosc Percutan Tech 2013; 23: $8-20$

[197] Puli SR, Graumlich JF, Pamulaparthy SR et al. Endoscopic transmural necrosectomy for walled-off pancreatic necrosis: a systematic review and meta-analysis. Can J Gastroenterol Hepatol 2014; 28: 50 53

[198] Haghshenasskashani A, Laurence JM, Kwan V et al. Endoscopic necrosectomy of pancreatic necrosis: a systematic review. Surg Endosc 2011; 25: $3724-3730$

[199] Bausch D, Wellner U, Kahl S et al. Minimally invasive operations for acute necrotizing pancreatitis: comparison of minimally invasive retroperitoneal necrosectomy with endoscopic transgastric necrosectomy. Surgery 2012; 152: S128-S134

[200] Tan V, Charachon A, Lescot T et al. Endoscopic transgastric versus surgical necrosectomy in infected pancreatic necrosis. Clin Res Hepatol Gastroenterol 2014; 38: 770 - 776

[201] Gurusamy KS, Belgaumkar AP, Haswell A et al. Interventions for necrotising pancreatitis. Cochrane Database Syst Rev 2016; 4: CD011383

[202] Rana S, Bashin D, Rao C et al. Consequences of long term indwelling transmural stents in patients with walled off pancreatic necrosis \& disconnected pancreatic duct syndrome. Pancreatology 2013; 13: 486-490

[203] Varadarajulu S, Wilcox CM. Endoscopic placement of permanent indwelling transmural stents in disconnected pancreatic duct syndrome: Does benefit outweigh the risks? Gastrointest Endosc 2011; 74: $1408-1412$

[204] Arvanitakis M, Delhaye M, Bali MA et al. Pancreatic-fluid collections: a randomized controlled trial regarding stent removal after endoscopic transmural drainage. Gastrointest Endosc 2007; 65: 609619

[205] Walter D, Will U, Sanchez-Yague A et al. A novel lumen-apposing metal stent for endoscopic ultrasound-guided drainage of pancreatic fluid collections: a prospective cohort study. Endoscopy 2015; 47: $63-67$

[206] Devière ], Antaki F. Disconnected pancreatic tail syndrome: a plea for multidisciplinarity. Gastrointest Endosc 2008; 67: 680-682

[207] Wong Y-C, Wang L-J, Fang J-F et al. Multidetector-row computed tomography (CT) of blunt pancreatic injuries: can contrast-enhanced multiphasic $\mathrm{CT}$ detect pancreatic duct injuries? J Trauma 2008; 64: 666-672

[208] Itoh S, Ikeda M, Ota T et al. Assessment of the pancreatic and intrapancreatic bile ducts using $0.5-\mathrm{mm}$ collimation and multiplanar reformatted images in multislice CT. Eur Radiol 2003; 13: 277- 285
[209] Drake LM, Anis M, Lawrence C. Accuracy of magnetic resonance cholangiopancreatography in identifying pancreatic duct disruption. J Clin Gastroenterol 2012; 46: 696-699

[210] Sherman S, Freeman ML, Tarnasky PR et al. Administration of secretin (RG1068) increases the sensitivity of detection of duct abnormalities by magnetic resonance cholangiopancreatography in patients with pancreatitis. Gastroenterology 2014; 147: 646-654

[211] Varadarajulu S, Noone TC, Tutuian R et al. Predictors of outcome in pancreatic duct disruption managed by endoscopic transpapillary stent placement. Gastrointest Endosc 2005; 61: 568 - 575

[212] Telford JJ, Farrell J], Saltzman JR et al. Pancreatic stent placement for duct disruption. Gastrointest Endosc 2002; 56: 18-24

[213] Shrode CW, MacDonough P, Gaidhane M et al. Multimodality endoscopic treatment of pancreatic duct disruption with stenting and pseudocyst drainage: How efficacious is it? Dig Liver Dis 2013; 45: $129-133$

[214] Pelaez-Luna M, Vege SS, Petersen BT et al. Disconnected pancreatic duct syndrome in severe acute pancreatitis: clinical and imaging characteristics and outcomes in a cohort of 31 cases. Gastrointest Endosc 2008; 68: 91 - 97

[215] Lawrence C, Howell DA, Stefan AM et al. Disconnected pancreatic tail syndrome: potential for endoscopic therapy and results of longterm follow-up. Gastrointest Endosc 2008; 67: 673-679

[216] Howard T], Rhodes G], Selzer DJ et al. Roux-en-Y internal drainage is the best surgical option to treat patients with disconnected duct syndrome after severe acute pancreatitis. Surgery 2001; 130 : 714 721

[217] Pearson EG, Scaife CL, Mulvihill S] et al. Roux-en-Y drainage of a pancreatic fistula for disconnected pancreatic duct syndrome after acute necrotizing pancreatitis. HBP 2012; 14: $26-31$

[218] Tann M, Maglinte D, Howard T] et al. Disconnected pancreatic duct syndrome: imaging findings and therapeutic implications in 26 surgically corrected patients. J Comput Assist Tomogr 2003; 27: $577-$ 582

[219] Bang JY, Wilcox CM, Navaneethan U et al. Impact of disconnected pancreatic duct syndrome on the endoscopic management of pancreatic fluid collections. Ann Surg; doi:10.1097| SLA.0000000000002082

[220] Sikora SS, Khare R, Srikanth G et al. External pancreatic fistula as a sequel to management of acute severe necrotizing pancreatitis. Dig Surg 2006; 22: $446-451$

[221] Bakker O], van Baal MC, van Santvoort HC et al. Endoscopic transpapillary stenting or conservative treatment for pancreatic fistulas in necrotizing pancreatitis: multicenter series and literature review. Ann Surg 2011; 253: 961 - 967

[222] Karjula H, Saarela A, Vaarala A et al. Endoscopic transpapillary stenting for pancreatic fistulas after necrosectomy with necrotizing pancreatitis. Surg Endosc Other Interv Tech 2014; 29: 108-112

[223] Boerma D, Rauws EA], Van Gulik TM et al. Endoscopic stent placement for pancreaticocutaneous fistula after surgical drainage of the pancreas. Br J Surg 2000; 87: 1506-1509

[224] Gomatos IP, Halloran CM, Ghaneh P et al. Outcomes from minimal access retroperitoneal and open pancreatic necrosectomy in 394 patients with necrotizing pancreatitis. Ann Surg 2016; 263: 992 1001

[225] Connor S, Alexakis N, Raraty MGT et al. Early and late complications after pancreatic necrosectomy. Surgery 2005; 137: 499- 505

[226] Beck WC, Bhutani MS, Raju GS et al. Surgical management of late sequelae in survivors of an episode of acute necrotizing pancreatitis. J Am Coll Surg 2012; 214: 682-628

[227] Arvanitakis M, Delhaye M, Bali MA et al. Endoscopic treatment of external pancreatic fistulas: When draining the main pancreatic duct is not enough. Am J Gastroenterol 2007; 102: 516- 524 